\title{
OF IRIDIUM (I)
}

Romeo Charles

Degree of Master of Science

Chemistry Department

McGill University

Montreal

\section{ABSTRACT}

The oxidative addition reaction of several silicon hydrides to hydridocarbonyltris (triphenylphosphine)iridium(I) was studied. Stable products were obtained in the cases of trichlorosilane, triphenylsilane, triethoxysilane, methyldichlorosilane and phenyldimethylsilane. Trimethylsilane also reacted but the product formed was unstable in the absence of excess trimethylsilane.

The adducts were of the type $\operatorname{Ir}(\mathrm{CO}) \mathrm{H}_{2} \mathrm{P}_{2} \mathrm{SiR}_{3}$. The stereochemistry of these adducts was established by proton nmr and infrared spectroscopies, and was shown to be;

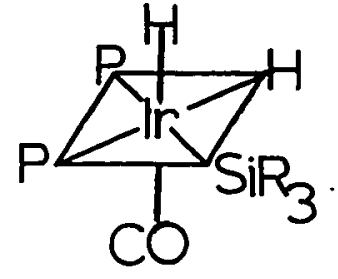

Hydridocarbonyltris (triphenylphosphine)iridium(I) was prepared in high yield by the dehydrochlorination of chlorodihydridocarbonylbis (triphenylphosphine)iridium(III) with ethanolic solution of potassium hydroxide in the presence of excess triphenylphosphine. 
OXIDATIVE ADDITION REACTION

OF IRIDIUM(I) 
OXIDATIVE ADDITION OF SILICON HYDRIDES

TO

HYDRIDOCARBONYLTRIS (TRIPHENYLPHOSPHINE) IRIDIUM (I)

by

Romeo Charles

A Thesis submitted to the Faculty of Graduate Studies and Research of McGill University in partial fulfillment of the requirements for the degree of Master of Science.

From the Department of Chemistry under the supervision of Dr. J.F. Harrod.

(c) Romeo Charles 1969 


\section{ACKNOWLEDGEMENTS}

The author wishes to express his gratitude to Dr. J.F. Harrod for his encouragement and assistance throughout the research program.

The author wishes to thank Dr. D.F.R. Gilson for the ${ }^{1} \mathrm{H}$ N.M.R. measurements. 
CONTENTS

PAGE

NO.

$\begin{array}{lll}\text { Chapter } 1 & \text { INTRODUCTION } & 1\end{array}$

A. HOMOGENEOUS CATALYSIS 1

(i). Hydrogenation 2

(ii). Hydrosilation 5

B. OXIDATIVE ADDITION 8

C. SOME PREPARATIONS AND PROPERTIES OF IRIDIUM-HYDRIDE COMPLEXES $\quad 12$

(i). Synthetic Methods 12

(ii). Characterization of iridium hydrides 14

(a). Nuclear Magnetic Resonance Studies 14

(b). Infrared studies 20

D. SOME REPORTED REACTIONS OF HYDRIDOCARBONYLTRIS (TRIPHENYLPHOSPHINE) IRIDIUM (I) 26

E. OUTLINE OF THE PRESENT RESEARCH PROGRAM 28

$\begin{array}{lll}\text { Chapter } 2 & \text { EXPERIMENTAI } & 30\end{array}$

$\begin{array}{lll}\text { Chapter } 3 & \text { RESULTS } & 41\end{array}$

Chapter 4 DISCUSSION 53

A. SILYLIRIDIUM (III) COMPIEXES 53

(i). General Properties 53

(ii). Proton nmr Spectra 54 
(iii). Infrared Spectra

B. THERMAL STABILITY

C. EXCHANGE WITH DEUTERIUM

Chapter 5 DEHYDROCHLORINATION OF CHLORODIHYDRIDO-

CARBONYLBIS (TRIPHENYLPHOSPHINE) IRIDIUM (III)

64

Chapter 6 A. CONCLUSIONS 69

B. SUGGESTIONS

$\begin{array}{ll}\text { APPENDIX } & 77\end{array}$

$\begin{array}{ll}\text { BIBLIOGRAPHY } & 78\end{array}$ 


\section{Chapter 1}

INTRODUCTION

\section{A. HOMOGENEOUS CATALYSIS}

Spurred by a growing interest in homogeneous catalysis (19), emphasis has recently been given to reactions of organo-transition metal complexes. This field of research has been particularly stimulated by the results of closely related work in heterogeneous catalysis, organic chemistry, biochemistry and by industrial interest.

In heterogeneous systems, the catalytic process must necessarily take place on the surface of the catalyst since only this is exposed to the reactants. Homogeneous catalysts are, however, soluble in the same medium as the reactants, and consequently all the molecules of the catalyst are available for an interaction. Thus, in terms of the fraction of catalyst participating, homogeneous catalysts are potentially more efficient than heterogeneous catalysts.

The field of homogeneously catalysed reactions is very large and expanding rapidly. However, only hydrogenation and hydrosilation catalysed reactions are closely related to the work undertaken in this present investigation; thus, discussion of the other classifications will be ignored. 


\section{(i). Hydrogenation}

Numerous compounds have been found which activate molecular hydrogen in solution and which catalyse the hydrogenation of olefins under homogeneous conditions. Among them are complexes of $\mathrm{Ru}(\mathrm{II})$ (1), $\mathrm{Pt}$ (II) (2), Co(II) (10), $\operatorname{Ir}(I)$ (4), $\operatorname{Rh}(I)$ (5), $\mathrm{Co}(I)$ (16) and $\mathrm{Fe}(0)$ (7).

The insertion of olefins into metal-hydrogen bonds is thought to be commonly found in olefin hydrogenation. The metal-hydrogen bond may originate from two sources, (a) the result of an intermediate formed when the catalyst itself is hydrogenated, or (b) the catalyst itself may be a transition metal complex containing the hydrido ligand. A vacant co-ordination site is perhaps the single most important property of a homogeneous catalyst. For this reason most mechanisms which have been proposed stress the importance of this factor $(5,44)$.

Catalytic systems involving chlorotris(triphenylphosphine)rhodium(I), $\operatorname{RhClP}_{3}^{*}$ have been studied in some detail (5). $\mathrm{RhClP}_{3}$ as a catalyst is remarkably effective for the hydrogenation of isolated double or triple bonds. A mechanism for this catalyst has been proposed using a combination of chemical and kinetic evidence. The complex in solution is known to dissociate, losing one triphenyl-

\footnotetext{
* Throughout this thesis $\mathrm{P}$ will be used to denote $\left(\mathrm{C}_{6} \mathrm{H}_{5}\right)_{3} \mathrm{P}$.
} 
phosphine molecule:

$$
\mathrm{RhClP}_{3} \stackrel{\text { soln. }}{\rightleftharpoons} \mathrm{RhClP}_{2}(\mathrm{~s})+\mathrm{P}
$$

This leaves a vacant site on the complex, which in solution is probably occupied by a solvent molecule (S). This solvated complex reacts very rapidly with molecular hydrogen to form an octahedral dihydrido species, $\operatorname{RhClP}_{2} \mathrm{H}_{2}(\mathrm{~S})$, containing two cis metal-hydrogen bonds, as confirmed by spectroscopic data. The ability of certain four co-ordinate square planar complexes to increase their co-ordination to six in this way by reaction with small molecules such as hydrogen is well known (47). (These addition reactions are discussed below in Section B). This dihydrido intermediate has one co-ordination site vacant or occupied by solvent. The existence of such a site is of great importance to the catalytic reactivity of this intermediate species since it allows the olefin to be activated at this site by displacement of the solvent:<smiles>[R17][R17](=O)[SnH3]</smiles>

Finally the hydrogenated product dissociates from the complex, which can then rejoin the catalytic cycle. It must be noted that the weakly held solvent molecule is cis to both hydride ligands, and consequently the transfer of 
the hydrogens to the olefin on the catalyst will involve cis addition. However the detailed mechanism of the transfer cannot be readily ascertained.

Square planar carbonyl complexes of iridium(I) and rhodium (I) of the type trans- $\left(M X(C O) P_{2}\right)$ (M=Ir, Rh. $X=C l$, $\mathrm{Br}, \mathrm{I})$, have been reported (9) to catalyse reactions of ethylene, propylene and acetylene with molecular hydrogen in benzene solutions at subatmospheric pressures of the reacting gases and at relatively mild temperatures. The iridium complexes react reversibly with molecular hydrogen. These adducts have been isolated and characterized, and the molecular configurations of these catalytic intermediates have been established by infrared and nmr measurements. The iridium complexes also react reversibly with ethylene and acetylene. Such reversible oxidative-addition reactions are essential steps in the mechanisms of most homogeneous catalysed systems.

Catalytic systems involving transition metal complexes containing the hydrido ligand have been studied (10). It has been postulated that their catalytic activity is connected with the presence of low-lying unfilled orbitals on the metal, especially those with a high degree of $d$ character, which can form weak bonds with the hydride ion by accepting electrons from it. The character of these and hence the catalytic activity of the complexes is greatly 
modified by the nature of the other ligands in the complex. Halpern (11) has pointed out that the large activation barriers which reflect the high dissociation energy of the hydrogen molecule (about $103 \mathrm{kcal} / \mathrm{mole}$ ) can be partially overcome by the use of suitable hydrido transition metal complexes as catalysts.

Dicobalt octacarbonyl (3) was one of the earliest known compounds believed to be capable of activating molecular hydrogen. However, its reaction with hydrogen (45) readily gives cobalt hydrocarbonyl and it is this hydrido complex that acts effectively as a homogeneous catalyst in hydrogenation reactions (46). Vaska (4) has used hydridocarbonyltris (triphenylphosphine) iridium (I), $\operatorname{Ir}(\mathrm{CO}) \mathrm{HP}_{3}$, as a catalyst in the hydrogenation of ethylene. $\operatorname{IrH}_{3} \mathrm{P}_{3}$ is reported (12) to catalyse the homogeneous hydrogenation of aldehydes and some olefins at $50^{\circ} \mathrm{C}$ and one atmosphere.

(ii). Hydrosilation

A reaction closely related to hydrogenation which is catalysed by complexes of Pt(II) (13), $\mathrm{Rh}(\mathrm{I})$ (15), Co(I) and Co(0) (16) has been reported by Harrod and Chalk (14) and by wilkinson (15). This reaction involves the catalytic addition of a silicon hydride to an olefinic double bond 
as represented by the following equation:

$$
\mathrm{RCH}=\mathrm{CH}_{2}+\mathrm{R}_{3}^{\prime} \mathrm{SiH} \longrightarrow \mathrm{RCH}_{2} \mathrm{CH}_{2} \mathrm{SiR}_{3}^{\prime}
$$

The mechanism advanced for the hydrogenation reaction requires that the metal ion both co-ordinate olefin and cleave the bond of molecular hydrogen. Consequently olefin co-ordination and $\mathrm{Si}-\mathrm{H}$ bond cleavage are the most probable functions of the metal catalyst in the hydrosilation reaction.

The role of group VIII metal complexes as hydrosilation catalysts has been discussed in terms of analogies between the reactions of such complexes with silicon hydride and with hydrogen (14). The four basic types of reaction between transition metal ions and hydrogen or silicon hydride are:

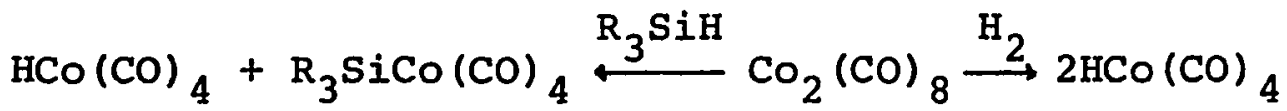

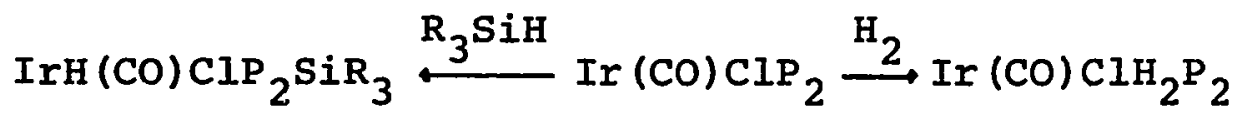

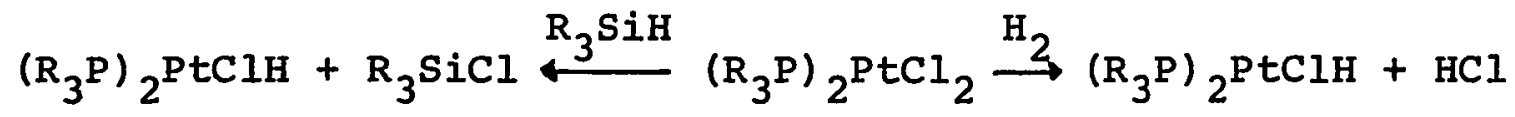

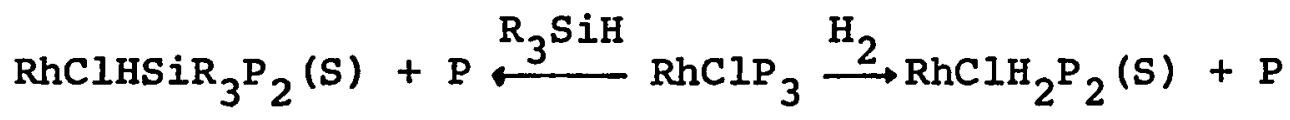

The reaction of dicobalt octacarbonyl illustrates a reaction in which a covalent bond is cleaved by two metal atoms, each metal atom accepting a fragment of the cleaved molecule. 
In reaction [5] a single metal ion captures both fragments of the cleaved molecule, while undergoing an increase of two in both its oxidation and co-ordination numbers. Reaction [6] illustrates the heterolytic cleavage of a covalent molecule leading to ligand substitution, but no change in oxidation or co-ordination number of the metal ion. Reaction [7] is similar to reaction [5] in as much as the metal ion captures both fragments of the cleaved molecule, but in doing so it loses a neutral ligand, whose vacant site is now occupied by a neutral solvent molecule. 


\section{B. OXIDATIVE ADDITION}

In hydrogenation and hydrosilation sections (pp2-7) brief mention was made of oxidative addition reactions. Such reactions may be schematically represented as in equation [8]:

$$
\mathrm{M}+\mathrm{XY} \longrightarrow \mathrm{XMY}
$$

In these reactions, one reactant (M) captures both fragments of the cleaved addend (XY), while undergoing an increase in its oxidation and co-ordination numbers.

Several homogeneous catalytic processes involve reversible oxidative additions as essential steps in their mechanisms. For this reason oxidative addition reactions involving four and five co-ordinate $d^{8}$ complexes is a subject of considerable current interest (47). Complexes of metals having $d^{8}$ configuration are often converted into octahedral $a^{6}$ complexes by addition of a covalent molecule to the co-ordination sphere.

Attention was drawn to these additions by Vaska's discovery of chlorocarbonylbis(triphenylphosphine)iridium(I), Ir $\left(\mathrm{CO} \mathrm{ClP}_{2}\right.$, (17). This complex undergoes a number of oxidative addition reactions. Examples of covalent molecules which add to the more reactive $\mathrm{d}^{8}$ complexes are $\mathrm{Cl}_{2}, \mathrm{Br}_{2}$, $\mathrm{I}_{2}(18)$, alkyl and aryisulfonyl chlorides $\left(\mathrm{RSO}_{2} \mathrm{Cl} ; \mathrm{R}=\right.$ alkyl or aryl) (22), silicon hydrides $\left(\mathrm{R}_{3} \mathrm{SiH} ; \mathrm{R}_{3}=\mathrm{Cl}_{3},\left(\mathrm{C}_{2} \mathrm{H}_{5} \mathrm{O}\right)_{3}\right.$, 
$\mathrm{C}_{2} \mathrm{H}_{5} \mathrm{Cl}_{2}, \mathrm{C}_{6} \mathrm{H}_{5} \mathrm{Cl}_{2}$ ) (14), methyl iodide (25), methyl chloride (25), hydrogen (18), hydrogen halides (21), tin(IV) chloride (20), and mercuric chloride, bromide and iodide (24).

These reversible additions of co-ordinatively unsaturated $d^{8}$ complexes often occur in a stereospecific manner, both cis and trans modes of addition have been observed depending on the reagent and the medium $(18,25)$,

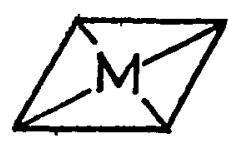

$+A-B$
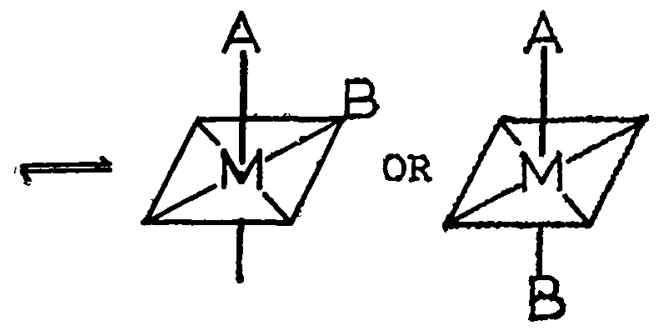

[9]

Co-ordinatively saturated $d^{8}$ complexes; usually having a trigonal-bipyramidal configuration, react with polar or highly polarizable addenda such as protonic acids (23), mercuric halides (31), halogens (23) and pseudo-halogens (23) to give octahedral $d^{6}$ complexes, losing a neutral ligand in the process. Collman (23) has suggested a two-step mechanism, in which the electrophile forms a bond with the central metal in the trigonal plane as an intermediate, with the second step 
$-\quad-10-$

being the irreversible loss of a neutral ligand:

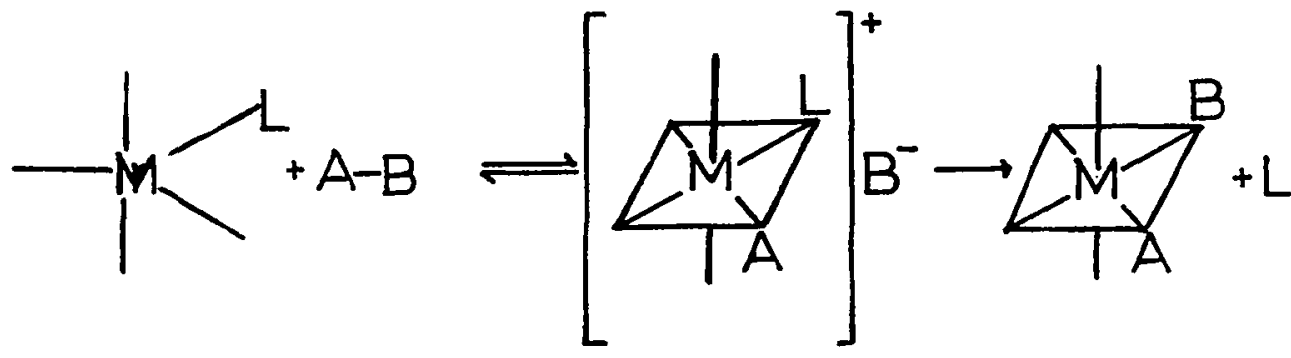

Alternatively five co-ordinate $d^{8}$ complexes can react through dissociation of a ligand prior to oxidative addition:
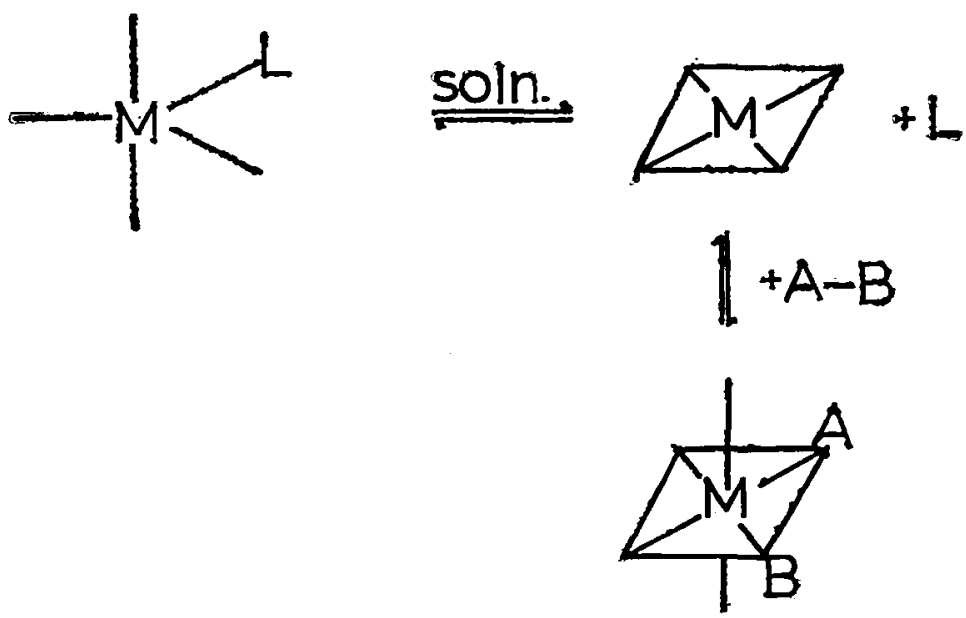

o

The final products of oxidative addition to saturated $a^{8}$ complexes are those resulting from overall cis addition.

Collman has recently reviewed (47) the factors 
influencing oxidative addition reactions. Most of the examples of oxidative addition reported have indicated that the tendencies for $d^{8}$ complexes to undergo oxidative addition depend markedly on (i) the nature of the central metal ion and (ii) the ligands. Ligands which increase electron density at the central metal enhance the tendency of a complex to undergo oxidative addition; the equilibrium constant for the hydrogen adduct of halogenocarbonylbis (triphenylphosphine) iriđium (I), Ir (CO) $\mathrm{XP}_{2}$ ' is greater for $X=I$ than for $X=C l$ (53). The propensity of $d^{8}$ metal ions to undergo oxidative addition increases upon descending a triad or passing from right to left along a period. This can be illustrated by considering the reaction of hydrogen, a reagent which adds to only the most reactive $d^{8}$ complexes. Whereas the iridium(I) carbonyl, $\operatorname{Ir}(\mathrm{CO}) \mathrm{ClP}_{2}$, readily forms an adduct with hydrogen, the isostructural rhodium(I) does not (18).

From a survey of the known oxidative addition reactions of $d^{8}$ complexes, an approximate order of reactivity has been assigned as follows:

Os $(\mathrm{O})>\mathrm{Ru}(\mathrm{O}) \sim \operatorname{Ir}(\mathrm{I})>\mathrm{Fe}(\mathrm{O}) \sim \mathrm{Rh}(\mathrm{I})>\mathrm{Pt}(\mathrm{II})>\mathrm{Co}(\mathrm{I}) \sim \mathrm{Pd}(\mathrm{II})>>\mathrm{Ni}(\mathrm{II})$. 


\section{SOME PREPARATIONS AND PROPERTIES OF IRIDIUM-HYDRIDE COMPLEXES}

Since the discovery (34) of the volatile chlorohydride of platinum, trans- $\left(\mathrm{PtHCl}\left(\mathrm{P}\left(\mathrm{C}_{2} \mathrm{H}_{5}\right)_{3}\right)_{2}\right.$ a large number of transition-metal hydrides stabilised by tertiary phosphines has been reported $(48,49)$. Among the transition metals studied, iridium has received considerable attention since it forms very stable hydride complexes. There are many ways of preparing these hydrides.

\section{(i). Synthetic Methods}

The most commonly used preparative route is the reduction of the metal halide (not fluoride) to the corresponding hydride using reducing agents such as sodium borohydride (35), lithium aluminium hydride (36) and hydrazine (38):
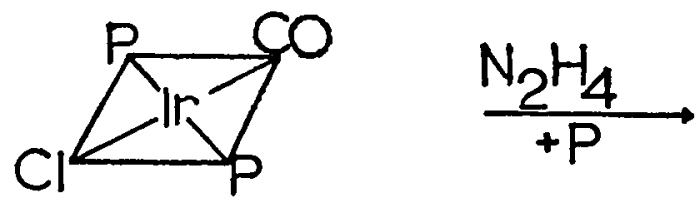<smiles>O=[I+2](F)(F)F</smiles><smiles>FC1(Cl)C2(Cl)C(Cl)(Cl)C(Cl)(Cl)C1(Cl)C2(Cl)Cl</smiles>

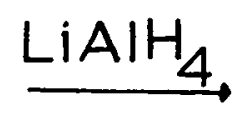<smiles>[2H][IH]</smiles>

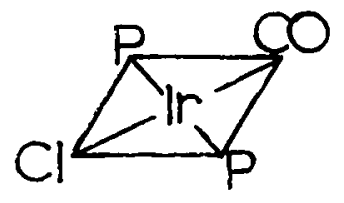

$\underline{\mathrm{NaBH}_{4}}$.<smiles>COc1ccccc1</smiles> 
An unexpected but versatile route to hydrides involves the reduction of the metal halides (not fluoride) by alcohols in basic media. This route is particularly useful for the preparation of iridium hydrides of the type $\left(\operatorname{IrH}_{\mathrm{X}} \mathrm{Y}_{3-\mathrm{x}}\left(\mathrm{MR}_{3}\right)_{3}\right) \quad(\mathrm{x}=1-3 ; \mathrm{Y}=\mathrm{Cl}, \mathrm{Br}, \mathrm{I} ; \mathrm{M}=\mathrm{P}$ or As; $\mathrm{R}=a 1 k y l$ or aryl group) (36). In a simple case, using ethanol and potassium hydroxide, the formation of the hydride is thought to proceed by way of displacement of the halogen by ethoxide ion, followed by a transfer of hydrogen from the ethyl group;

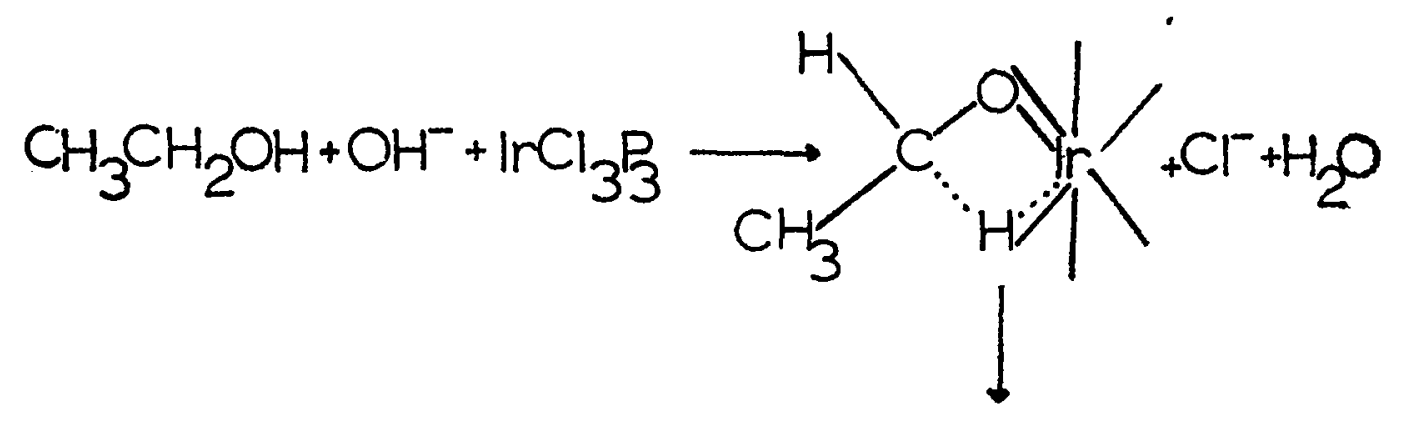

$$
\mathrm{Cl}+\mathrm{CH}_{3} \mathrm{CHO}+\mathrm{H}_{2} \mathrm{O}+\mathrm{IrHCl}_{2} \mathrm{P}_{3}
$$

In some cases, addition of molecular hydrogen will give a hydrido-species $(18,48,49)$;

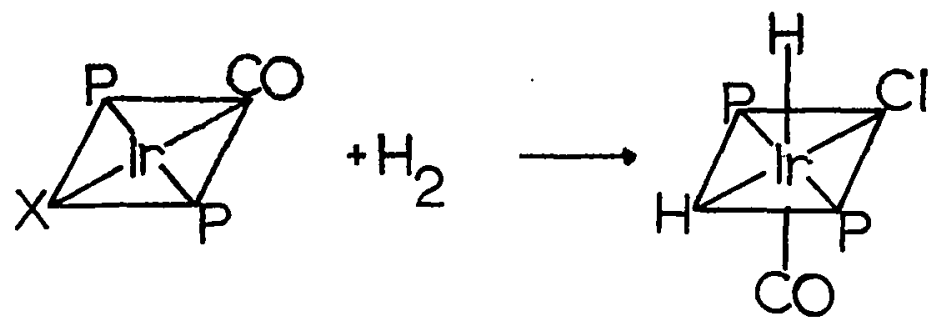

$\mathrm{X}=\mathrm{Cl}, \mathrm{Br}, \mathrm{I}$. 
(ii). Characterization of iridium-hydrides

Knowledge of the stereochemistry of initial and final products of oxidative addition reactions aid in determining the stereochemical course of these reactions. In reactions concerning homogeneous catalysis it is important that the compositions, properties and structures of the catalyst complexes and catalytic intermediates be known in order that mechanisms or stereochemical courses of reaction may be proposed.

The two basic tools used most frequently in determining stereochemistry of such complexes are high resolution nuclear magnetic resonance and far and near infrared spectroscopy. Combination of both methods has led to unequivocal assignments of stereochemistry of several complexes.

(a) Nuclear magnetic resonance studies

The rapid progress in the discovery and study of transition metal hydride complexes is largely due to the characteristic high field shift in the high resolution nuclear magnetic resonance spectrum exhibited to date by all hydrogens attached to transition metals.

The resonances of metal-hydrogens occur at $>12 \tau$, are frequently in the range 20-30 , and may occur as high as $45 \tau$. Spin-spin coupling of the metal-hydrogens with 
other nuclei in the complex, in particular with the central metal, observable with $\mathrm{Rh}, \mathrm{Pt}$ and $\mathrm{W}$ nuclei, provides strong evidence for direct metal-hydrogen bonds. However, so far there has been no reported interaction with the Ir ${ }^{192}$ nucleus, though coupling with other ligands attached to the central metal has been observed.

In the phosphine hydrides the $\mathrm{P}^{31}$ nucleus $(I=1 / 2)$ will couple with the hydrogen; for the P ligand trans to $\mathrm{H}, \mathrm{J}(\mathrm{P}-\mathrm{H})=80-160 \mathrm{~Hz}$; while for $\mathrm{P}$ cis to $\mathrm{H}$, $J(\mathrm{P}-\mathrm{H})=10-40 \mathrm{~Hz}$. Thus the phosphorus-hydrogen coupling can provide evidence for the configuration of various phosphine complexes. In some dihydrido complexes colpling between the non-equivalent hydrogens is observed, $J\left(\mathrm{H}_{1}-\mathrm{H}_{2}\right)=4-8 \mathrm{~Hz}$. Table I (p 17) lists chemical shifts and coupling constants for several phosphine iridium complexes.

In the complexes where the phosphine ligands are methyl substituted, Jenkins and Shaw (39) have demonstrated that it is possible to determine the relative positions of the methyl substituted phosphine ligands by nuclear magnetic resonance spectroscopy. In complexes having mutually trans phosphine Iigands the proton $\mathrm{nmr}$ spectrum of the $\left(\mathrm{PCH}_{3}\right)$ groups exhibits a triplet because of the strong coupling of the protons on the methyl groups with the mutually trans phosphine 1igands. However, if the the phosphine ligands 
are cis, they behave as isolated units and the $\left(\mathrm{PCH}_{3}\right)$ groups give rise to a doublet.

From Table 1 it is clearly evident that the positions of the phosphine ligands will govern the form of the resonance patterns. Protons trans to halogens clearly have much higher chemical shifts than the protons trans to phosphorus and carbon monoxide groups. On the other hand there appears to be no characteristic difference between the chemical shifts of protons trans to $\mathrm{P}$ and $\mathrm{CO}$. Not many examples of phosphine-carbonyl complexes are known from which a satisfactory comparison may be made. The above behaviour exemplifies the fact that phosphine and carbonyl ligands have comparable trans effects, whereas the halogens have much lower trans effect than $P$ and co. 


\section{TABLE 1}

NMR DATA ${ }^{a}$

CHEMICAL SHIFTS AND COUPLING CONSTANTS OF SEVERAL IRIDIUM-PHOSPHINE COMPLEXES ${ }^{b}$
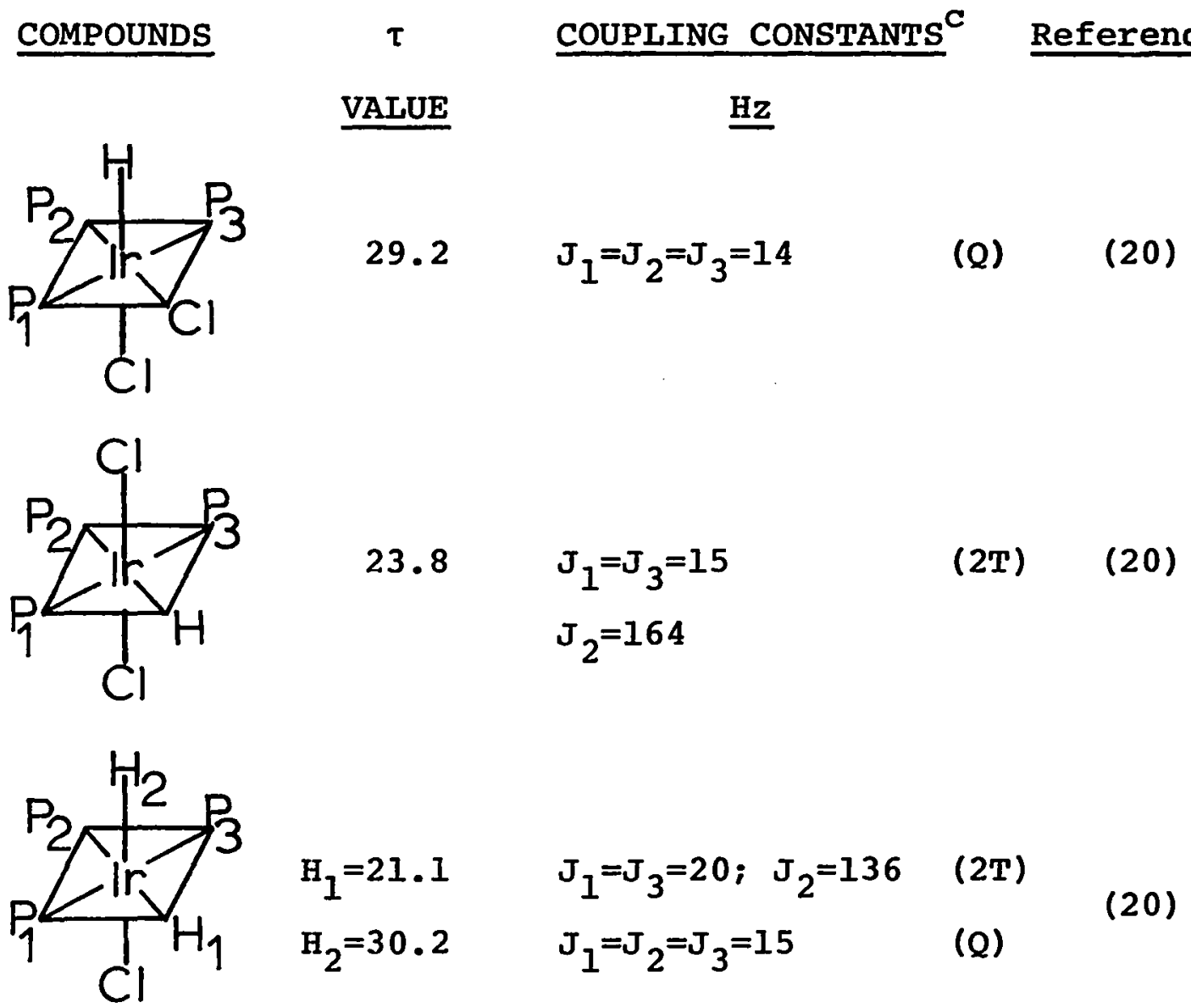

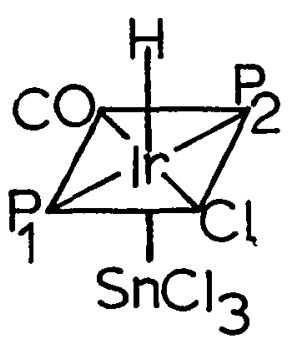

$$
19.9 \quad \mathrm{~J}_{1}=\mathrm{J}_{2}=10
$$

$(20)^{\mathrm{d}}$

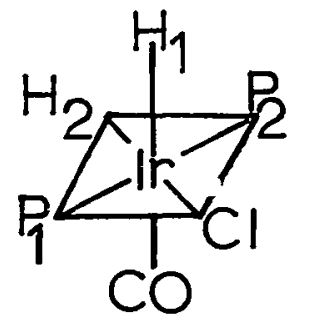

$$
\begin{array}{ll}
\mathrm{H}_{1}=17.3 & \mathrm{~J}_{1}=\mathrm{J}_{2}=15 \\
\mathrm{H}_{2}=28.4 & \mathrm{~J}_{1}=\mathrm{J}_{2}=15
\end{array}
$$


(2)<smiles>O=C1C2C3C4C1(Cl)C2(Cl)C34Cl</smiles>

$$
22.6 \quad \mathrm{~J}_{1}=\mathrm{J}_{3}=19 ; \mathrm{J}_{2}=158(2 \mathrm{~T}) \quad(36)^{\mathrm{f}}
$$

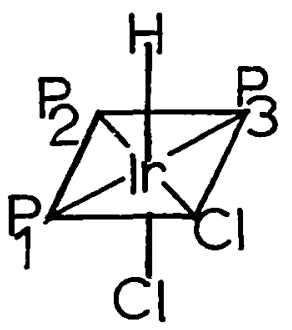

$31.2 \quad \mathrm{~J}_{1}=\mathrm{J}_{3}=12 ; \mathrm{J}_{2}=18 \quad(6$ lines $)(36)^{\mathrm{f}}$

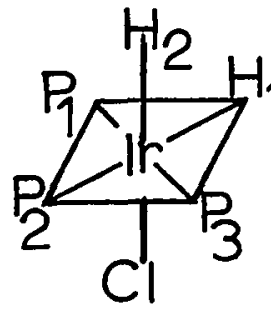

$$
\begin{aligned}
& \mathrm{H}_{1}=18.6 \\
& \mathrm{H}_{2}=31.5
\end{aligned}
$$

$\mathrm{J}_{1}=\mathrm{J}_{3}=19.9 ; \mathrm{J}_{2}=125$

(2T)

$\mathrm{J}_{1}=\mathrm{J}_{2}=\mathrm{J}_{3}=14.3$

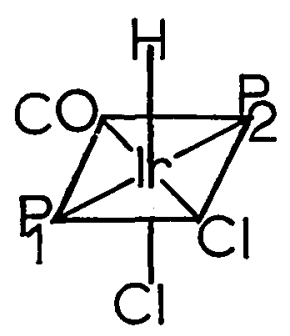

$$
26.05 \quad \mathrm{~J}_{1}=\mathrm{J}_{2}=12
$$

(T) $\quad(51)^{d, f}$

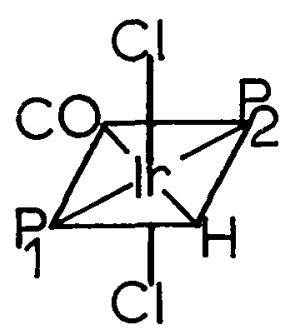

$$
19.0 \quad \mathrm{~J}_{1}=\mathrm{J}_{2}=16
$$

(T) $\quad(51)^{d, f}$ 


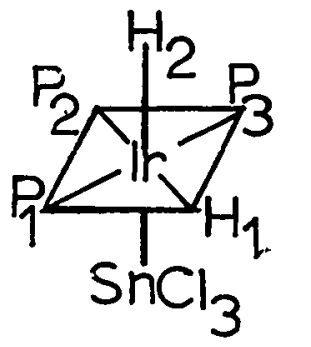

$$
\begin{array}{ll}
\mathrm{H}_{1}=22.2 & \mathrm{~J}_{1}=\mathrm{J}_{3}=10 ; \mathrm{J}_{2}=153 \\
\mathrm{H}_{2}=24.7 & \mathrm{~J}_{1}=\mathrm{J}_{2}=\mathrm{J}_{3}=20
\end{array}
$$

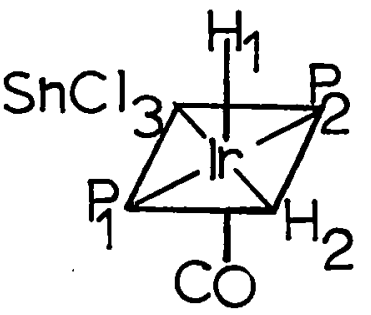

$$
\begin{array}{ll}
\mathrm{H}_{1}=19.9 & \mathrm{~J}_{1}=\mathrm{J}_{2}=10 \\
\mathrm{H}_{2}=22.5 & \mathrm{~J}_{1}=\mathrm{J}_{2}=10
\end{array}
$$

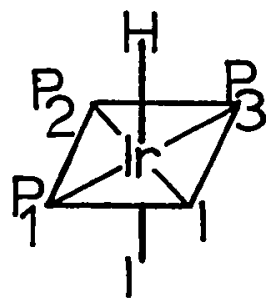

$$
29.3 \quad J_{1}=J_{3}=14 ; J_{2}=16(6 \text { lines })(39)^{e, f}
$$<smiles>[2H][I-]([2H])([2H])[18O-]</smiles>

21.2

$$
\mathrm{J}_{1}=\mathrm{J}_{2}=\mathrm{J}_{3}=24
$$<smiles>[2H][CH][2H]</smiles>

19.9

$\mathrm{J}_{1}=\mathrm{J}_{2}=13$

(T)

$(36)^{\mathrm{f}}$

a. Spectra taken in benzene unless otherwise stated.

b. All complexes are of triphenylphosphine unless stated otherwise.

c. $\mathrm{J}_{1}=\mathrm{J}\left(\mathrm{P}_{1}-\mathrm{H}\right), \mathrm{J}_{2}=\mathrm{J}\left(\mathrm{P}_{2}-\mathrm{H}\right), \mathrm{J}_{3}=\mathrm{J}\left(\mathrm{P}_{3}-\mathrm{H}\right)$. Multiple patterns indicated by $\mathrm{T}=$ triplet, $\mathrm{Q}=$ quartet. Splitting caused by $\mathrm{J}(\mathrm{H}-\mathrm{H})$ is not considered.

d. Spectra taken in dichloromethane.

e. Spectrum taken in chloroform.

f. These complexes are of phenyldiethylphosphine. 
(b) Infrared studies

The spectra of most iridium hydrides show bands in the region 1700-2200 $\mathrm{cm}^{-1}$, which are assigned to the iridium-hydrogen stretching frequencies. Table 2 (p 22) shows the iridium-hydrogen stretching frequencies of several iridium-phosphine complexes. As in the case of nmr spectroscopy, it is evident that the hydrogens trans to the halogens have much higher iridium-hydrogen stretching frequencies than when they are trans to phosphine or carbonyl groups. This is expected since phosphine and carbonyl ligands have higher trans effects than the halogens. Most iridium-hydrogen stretching frequencies are observed between $2000 \mathrm{~cm}^{-1}$ and $2200 \mathrm{~cm}^{-1}$ but frequencies as low as $1700 \mathrm{~cm}^{-1}$ have been observed and several authors $(35,36)$ have associated these frequencies with vibrations involving two hydrogens in mutual trans positions.

The carbonyl[ $\left.{ }^{\nu}(\mathrm{CO})\right]$ stretching motions in iridium-carbonyl complexes are very sensitive to the charge of the central metal ion, moving to higher frequencies as the positive charge on the metal ion increases. Such a strengthening of the $\mathrm{CO}$ bonding is expected since positive charge on the metal tends to reduce donation by the metal into the antibonding pi $(\pi)$ orbital of the carbonyl group. Table 2 (p 22) lists the carbonyl stretching frequencies of several iridium-carbonyl complexes. 
A resonance interaction between the vibrational states of metal-hydrogen and carbonyl [ ${ }^{\nu}(\mathrm{CO})$ ] stretching motions in certain hydridocarbonyl complexes of iridium was observed by Vaska (40). This interaction offers itself as a powerful aid in deducing the molecular structures of these and analogous compounds. In favourable cases a complete co-ordinated configuration of the central atom can be determined. The interaction occurs when the hydrogen and carbonyl ligands are trans to one another; it is not observed when the two ligands occupy cis positions. A shift is observed in the carbonyl stretching frequency $\left[{ }^{\nu}(\mathrm{CO})\right]$ when the hydrogen trans to the carbonyl group is replaced by deuterium; no such shift is observed when the hydrogen cis to the carbonyl is replaced by deuterium.

Jenkins and Shaw (4l) have studied the far infrared adsorption spectra of a series of halogenoiridium(III) complexes containing tertiary phosphine as ligands. From their studies, they observed that the iridium-chlorine frequency depends primarily on the nature of the ligand trans to the chlorine and is insensitive to the cis ligands. Several authors. (30) then have used this mean as a useful aid in assigning stereochemistry to several halogeno-iridium(III) complexes. 
TABLE 2

INFRARED DATA ${ }^{a}$

IRIDIUM-HYDROGEN AND CARBONYL STRETCHING FREQUENCIES OF

SOME IRIDIUM COMPLEXES

COMPOUNDS

$\frac{\nu(\operatorname{Ir}-\mathrm{H})}{\mathrm{cm}^{-1}} \quad \frac{\nu(\mathrm{CO})}{\mathrm{cm}^{-1}}$

$\underline{\text { References }}$<smiles>CC1(C)CCCC1(F)F</smiles>

$$
\mathrm{H}_{1}=2080
$$

1955

$(35)^{e}$

$\mathrm{H}_{2}, \mathrm{H}_{3}=1780$<smiles></smiles>

$\mathrm{H}_{1}, \mathrm{H}_{2}=1755$

$\mathrm{H}_{3}=2104$

$(36)^{e}$<smiles></smiles>

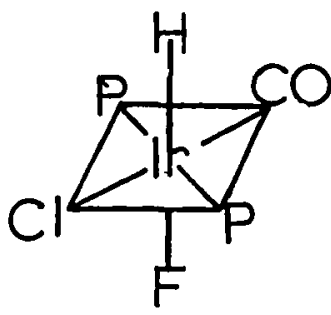



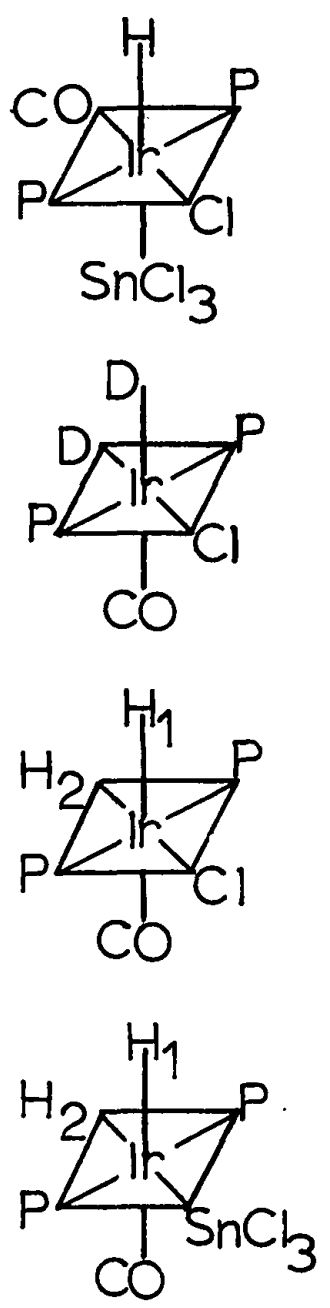

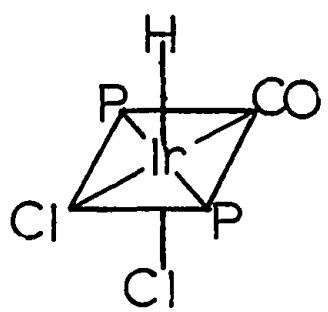

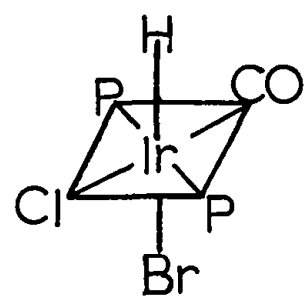

2148

2053

(20)

2003

(40)

$\mathrm{H}_{1}=2100$

1982

(20)

$\mathrm{H}_{2}=2196$

$\mathrm{H}_{1}=2014$

2062

$(20)^{b}$

$\mathrm{H}_{2}=2112$

2240

2024

(20)

2240

2022

(52) 


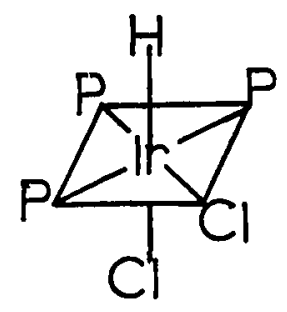

2228
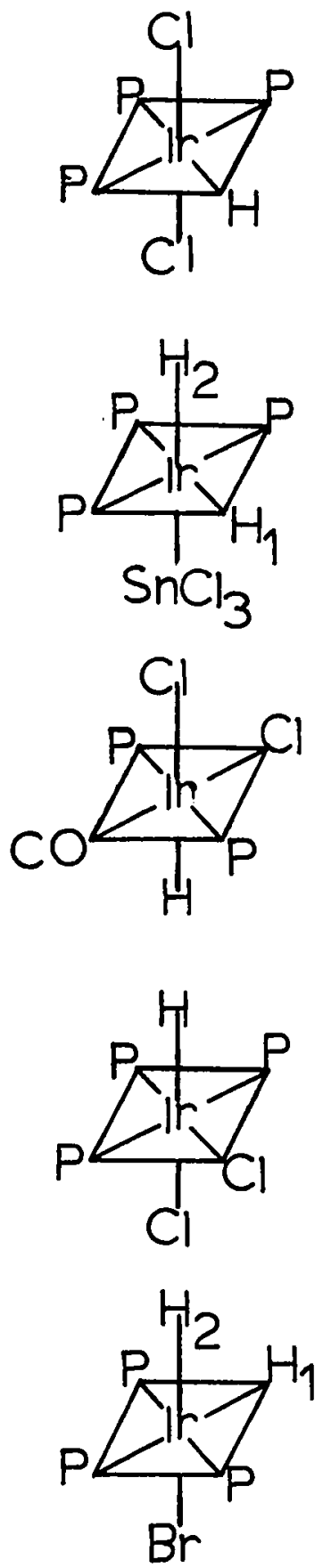

$\mathrm{H}_{1}=2205$

$\mathrm{H}_{2}=2262$

2189
$\mathrm{H}_{1}=2020$ $(20)^{c}$

(20) $(36)^{\mathrm{C}}$ 
<smiles></smiles>

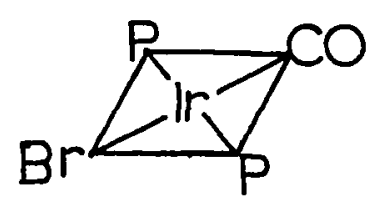<smiles>OC12C3C1P32</smiles><smiles>C12C3C1P23</smiles><smiles>O=I(F)(F)F</smiles><smiles></smiles><smiles>[3H][V]([3H])([3H])F</smiles>

a. Spectra taken in nujol unless otherwise stated.

b. Spectrum taken in chloroform.

c. $\quad \mathrm{P}$ in this complex represents phenyldiethylphosphine.

d. $P$ in this complex represents triethylphosphine.

e. Spectra taken in benzene. 
D. SOME REPORTED REACTIONS OF HYDRIDOCARBONYLTRIS (TRIPHENYLPHOSPHINE) IRIDIUM (I)

Several examples of oxidative addition to unsaturated iridium(I) complexes (mainly $\operatorname{Ir}(\mathrm{CO}) \mathrm{XP}_{2}$ ' where $\mathrm{X}=\mathrm{Cl}, \mathrm{Br}, \mathrm{I}$ ) have been reported (32) (cf. Chpt. 1, Section B of this thesis). However reactions with hydridocarbonyltris (triphenylphosphine)iridium (I) (a saturated iridium(I) complex) are few.

Most $d^{8}$ complexes are thought of as possessing basic properties and for this reason they may undergo protonation with little difficulty. Malatesta (33) has protonated the five co-ordinated hydride, $\operatorname{Ir}(\mathrm{CO}) \mathrm{HP}_{3}$, by the addition of perchloric acid, $\mathrm{HClO}_{4}$, to form a cationic six co-ordinated iridium(III) dihydride, $\left(\operatorname{Ir}(\mathrm{CO}) \mathrm{H}_{2} \mathrm{P}_{3}\right)^{+} \mathrm{ClO}_{4}{ }^{-}$.

Carbon monoxide has been reported (33) to react with hydridocarbonyltris (triphenylphosphine) iridium(I); the final products depending on temperature and pressure. At 200 atmospheres of carbon monoxide at room temperature the final product was reported to be an unsaturated iridium(I) complex, $\operatorname{Ir}(\mathrm{CO}) \mathrm{HP}_{2}$, but at 200 atmospheres pressure of carbon monoxide at $50^{\circ} \mathrm{C}$ in ethanol, the nature of the final product was doubtful. A dimer, $\left(\operatorname{Ir}(\mathrm{CO}){ }_{3}{ }^{\mathrm{P}}\right)_{2}$ and a monohydride, $\operatorname{Ir}(\mathrm{CO})_{3} \mathrm{HP}$, were suggested as final product. 
Vaska (4) has claimed that $\operatorname{Ir}(\mathrm{CO}) \mathrm{HP}_{3}$ is an efficient homogeneous catalyst for the reaction of molecular hydrogen with ethylene at ambient conditions. However individual experiments with hydrogen and ethylene (4) with $\operatorname{Ir}(\mathrm{CO}) \mathrm{HP}_{3}$ indicated that they reacted reversibly with $\operatorname{Ir}(\mathrm{CO}) \mathrm{HP}_{3}$ under normal conditions. In the case of hydrogen addition, the author suggested a seven co-ordinated trihydride complex without any chemical evidence:

$$
\operatorname{Ir}(\mathrm{CO}) \mathrm{HP}_{3}+\mathrm{H}_{2} \longrightarrow \operatorname{Ir}(\mathrm{CO}) \mathrm{H}_{3} \mathrm{P}_{3}
$$

The existence of a seven co-ordinated $d^{6}$ complex is doubtful, since electrons would have to be placed in antibonding orbitals to accommodate seven ligands in a complex of $d^{6}$ configuration. 


\section{E. OUTLINE OF THE PRESENT RESEARCH PROGRAM}

The oxidative addition of silicon hydrides to chlorocarbonylbis (triphenylphosphine) iridium (I) was previously studied (14) in an investigation of the mechanism of homogeneously catalysed hydrosilation. The complexes formed in the above reactions were not suitable for intensive structural investigation because of their instability in solution and because the reactions only occured with silicon hydrides with electronegative substituents.

It is the general purpose of the present investigation to study the oxidative addition of several silicon hydrides to hydridocarbonyltris (triphenylphosphine) iridium (I) .

These reactions were of interest because

firstly, the possibility existed for an unequivocal assignment of stereochemistry by proton $\mathrm{nmr}$ and infrared analyses, and secondly it was hoped that the reductive elimination of molecular hydrogen from the adducts would provide a synthetic route to the hitherto unknown silyltriphenylphosphineiridium(I) complexes.

The preparation of hydridocarbonyltris (triphenylphosphine)iridium(I) as outlined in the literature either 
gave poor yields (38) or was prepared by difficult, multistep routes (35). In the course of this research program, a simple synthesis with high overall yield was sought. 


\section{Chapter 2}

\section{EXPERIMENTAL}

Materials

Iridium trichloride trihydrate was obtained from Engelhard Co. as a crystalline solid. Silicon hydrides were obtained from Peninsular Chem Research and were purified by distillation on a vacuum line, rejecting the first and last quarter of the distillate. Triphenylsilane and trimethylsilane were used without further purification.

All solvents were dried by heating at reflux with calcium hydride for twenty-four hours.

${ }^{1}$ H nmr spectra

Spectra were measured on a Varian A-60 high resolution nuclear magnetic resonance spectrometer equipped with a C-1024 time averaging computer.

Tetramethylsilane $(10 \tau)$ was used as an internal reference for all samples. Measurements were made on $30 \%$ to 508 by weight solutions of the addurts in dichloromethane. 
under the following setting;

Spectrometer C-1024 'CAT'

Settings

Filter Band Width

R. F. Field

Sweep Time

Sweep Width

Sweep Offset

Spectrum Amplitude

Integral Amplitude
$2 \mathrm{~Hz}$

$0.7 \mathrm{mG}$

$250 \mathrm{sec}$

$250 \mathrm{sec}$

$500 \mathrm{~Hz}$

$500 \mathrm{~Hz}$

$-500 \mathrm{~Hz}$

$-500 \mathrm{~Hz}$

10.0 $2^{13}$

4.0

Only adducts of triphenylsilane, triethoxysilane and phenyldimethylsilane were sufficiently soluble to allow nmr measurements.

\section{Infrared spectra}

Spectra were measured on a Perkin-Elmer model 257 dual grating infrared spectrometer.

Samples were run as liquid smears between $\mathrm{NaCl}$ plates or as $\mathrm{KBr}$ pellets or in solutions with benzene or dichloromethane as solvents.

Each spectrum was frequency calibrated with a polystyrene film. 
Analysis

Adducts of triethoxysilane, triphenylsilane and trichlorosilane were analysed for $\mathrm{C}, \mathrm{H}, \mathrm{Si}$ and $\mathrm{P}$ content.

Analyses were by Swartzkopf Microanalytical Laboratories, New York.

Preparations

(i) Chlorocarbonylbis (triphenylphosphine)iridium (I)

This was prepared according to the method of Collman and Kang (27).

(ii) Chlorodihydridocarbonylbis (triphenylphosphine) iridium (III)

This was prepared according to the method of Vaska and DiLuzio (18).

(iii) Hydridocarbonyltris (triphenylphosphine) iridium (I)

Method (a)

This was prepared according to the method of Vaska and Bath (38).

Method (b)

A mixture of chlorodihydridocarbonylbis(triphenylphosphine)iridium(III) (3 g.), triphenylphosphine (3 g.) and ethanolic potassium hydroxide $(4 \mathrm{ml}$ of $0.9 \mathrm{M})$ in ethanol $(30 \mathrm{ml})$ was heated at reflux temperature under nitrogen. 
Test samples were taken every fifteen minutes and infrared spectra of samples were obtained.

After two hours under reflux, infrared spectrum of sample showed the disappearance of ${ }^{\nu}(\mathrm{Ir}-\mathrm{H})$ and ${ }^{\nu}(\mathrm{CO})$ stretching frequencies of the starting iridium(III) dihydride, and the appearance of two new stretching frequencies within the range $\left(1900-2200 \mathrm{~cm}^{-1}\right)$.

There was an obvious colour change from the pale yellow iridium(III) dihydride complex to the bright yellow iridium(I) monohydride complex. Both are insoluble in ethanol. After cooling to room temperature the yellow complex was collected on a filter and washed with ethanol ( $3 \times 30 \mathrm{ml})$. It was then dissolved in benzene $(2 \times 25 \mathrm{ml})$, and filtered. Solid potassium chloride (approx. $0.3 \mathrm{g.}$ ) was collected on the filter. The filtrate was finally placed on vacuum line and solvent removed. Yellow complex was recrystallized Irom benzene $(15 \mathrm{ml})$ ană hexane $(40 \mathrm{ml})$.

After crystallization, 3.2 grams of hydridocarbonyltris(triphenylphosphine) iridium(I) were collected.

$$
\text { Yield - } 86 \% \text { based on starting iridium(III) }
$$

dihydride. 
Interaction of silanes with hydridocarbonyltris (triphenylphosphine) iridium (I)

(iv). Triethoxysilane

A sample of hydridocarbonyltris(triphenylphosphine)iridium(I) $(0.3 \mathrm{g.})$ was dissolved in dried benzene $(5 \mathrm{ml})$ and placed on a vacuum transfer line. The solution was throughly degassed. Triethoxysilane $(1.2 \mathrm{g.})$ was distilled onto the solution of the iridium complex and the reactants left at room temperature for one hour. During this period, the initially golden-yellow solution became lighter in colour. After completion of reaction, all volatile material was pumped off by prolonged evacuation at room temperature. A yellow viscous liquid remained as residue. Light yellow crystals (approx. 0.24 g.) were then obtained by trituration of viscous liquid with hexane $(5 \mathrm{ml})$.

Yield - approx. $88 \%$.

The triethoxysilane may also be distilled onto the solid hydridocarbonyltris (tripinenylphosphine) iridium(I) on a vacuum transfer line. When this was done a yellow solution resulted. Apparently both the iridium(I) and iridium(III) complexes are soluble in the silane. Upon removal of excess silane, a similar yellow viscous liquid 
was obtained. Yellow crystals were then obtained by careful addition of hexane.

(v). Phenyldimethylsilane

The adduct of this silane was prepared in a similar manner as was for the case of the triethoxy adduct.

(vi). Triphenylsilane

A mixture of hydridocarbonyltris (triphenylphosphine)iridium(I) $(0.2183 \mathrm{g.})$ and triphenylsilane (0.0564 $\mathrm{g.})$ was dissolved in dried benzene $(15 \mathrm{ml})$ in a small beaker. The solution was stirred with a magnetic stirrer for ten minutes. The solvent volume was reduced (5-10 $\mathrm{mI})$ on vacuum line and upon careful addition of dried hexane, yellow-white crystals $(0.2 \mathrm{~g}$.$) precipitated$ out. These were collected on a filter and washed with some cold dried hexane ( $3 \times 5 \mathrm{ml})$.

$$
\text { Yield - approx. } 90 \% \text {. }
$$

(vii). Trichlorosilane

A sample of hydridocarbonyltris(triphenylphosphine)iridium(I) $(0.31 \mathrm{g.})$ was dissolved in dried benzene (5 $\mathrm{ml})$ in a vessel attached to a vacuum transfer line. Trichlorosilane $(0.6 \mathrm{~g}$.$) was degassed thoroughly and vacuum-distilled$ into the reaction vessel kept at liquid nitrogen temperature. 
The reaction vessel was then allowed to warm up to room temperature. It was left at this temperature for fifteen minutes. At the end of this period, the volume of the solution, which turned from golden-yellow to colourless, was reduced. When this was done white crystals $(0.23 \mathrm{~g}$.$) of the adduct precipitated out.$ These were filtered off under nitrogen, washed with a little cold dried benzene $(2 \times 5 \mathrm{ml})$ and dried in a vacuum.

\section{Yield - approx. $88 \%$}

The preparation can be carried out as above with pure silane as solvent. When this was done, the yellow iridium(I) complex changed to the white iridium(III) adduct at room temperature after only fifteen minutes. Both iridium complexes (I and III) are insoluble in the silane, unlike in the case of the triethoxysilane, where both complexes were soluble in the silane.

\section{(viii). Methyldichlorosilane}

By the same method described above in the case of trichlorosilane, white crystals of the methyldichlorosilyl adduct were obtained.

(ix). Trimethylsilane

Excess trimethylsilane was distilled onto a benzene 
solution (5 ml) of hydridocarbonyltris(triphenylphosphine)iridium(I) $(0.2 \mathrm{g.})$ in a reaction vessel kept at $0^{\circ} \mathrm{C}$. There was a definite colour change from yellow iridium(I) complex to a very pale yellow iridium(III) adduct. All attempts to isolate the adduct as a solid failed since solutions of the iridium(III) complex decomposed rapidly, giving the iridium(I) complex in solution. However a rapid reaction does take place in solution in presence of large excess of silane. Infrared measurements were made in presence of excess of silane.

Other Preparations

(x). Deuteridocarbonyltris (triphenylphosphine) iridium(I)

\section{Method (a)}

This was prepared according to the method of Vaska (42).

Method (b)

A mixture of chlorodideuteridocarbonylbis(triphenylphosphine)iridium(III) ( $3 \mathrm{g.})$, triphenylphosphine ( $3 \mathrm{g.}$ ) and ethanolic potassium hydroxide $(4 \mathrm{ml}$ of $0.9 \mathrm{M})$ in ethanol ( $30 \mathrm{ml})$ was heated at reflux under nitrogen for two hours.

After cooling to room temperature the yellow compound was collected on a filter and washed with ethanol $(3 \times 10 \mathrm{ml})$. It was then dissolved in benzene $(2 \times 25 \mathrm{ml})$ and filtered. The filtrate was finally placed on vacuum 
line and the solvent removed. The yellow complex was then recrystallized from benzene $(15 \mathrm{ml})$ and hexane $(40 \mathrm{ml})$.

(xi). Chlorodideuteridocarbonylbis (triphenylphosphine)iridium (III)

This was prepared according to the method of Vaska and DiLuzio (18).

(xii). Deuteridohydridotriethoxysilylbis (triphenylphosphine) iridium (III)

A sample of deuteridocarbonyltris (triphenylphosphine)iridium(I) was dissolved in dried benzene (5 ml) and placed on vacuum transfer line. The solution was then thoroughly degassed. Triethoxysilane $(3.2 \mathrm{ml}$ of $0.6 \mathrm{M}$ in benzene) was distilled onto the solution of iridium(I) complex and the reactants left at room temperature for one hour. After this period all volatile material was pumped off by prolonged evacuation at room temperature. A viscous yellow liquid remained, which gave yellow crystals upon careful addition of hexane.

(xiii). Trihydridocarbonylbis (triphenylphosphine) iridium (III) This was prepared according to the method of Malatesta et al (35). 
(xiv). Attempted preparations of hydridocarbonylbis (triphenylphosphine) iriaium (I)

Methods (a) and (b) were prepared according to the methods of Malatesta et al (35).

Method (a)

In this method, iridium tetraiodide was

carbonylated in the presence of triphenylphosphine and potassium hydroxide.

Method (b)

In this method, nitorgen was bubbled through a benzene solution of trihydridocarbonylbis(triphenylphosphine)iridium(III) for four hours.

Method (c)

A suspension of chlorodihydridocarbonylbis(triphenylphosphine)iridium(III) $(3 \mathrm{g.})$ in ethanol $(30 \mathrm{ml})$ was heated at reflux with ethanolic potassium hydroxide (4 ml of $0.9 \mathrm{M}$ ) under (i) nitrogen, (ii) hydrogen and (iii) carbon monoxide in three separate reactions. Test samples were taken every fifteen minutes and the infrared spectra of the samples were recorded. After 90 minutes under reflux the infrared spectra showed the disappearance of ${ }^{\nu}(\mathrm{Ir}-\mathrm{H})$ and ${ }^{\nu}(\mathrm{CO})$ stretching frequencies of the starting iridium(III) dihydride, and the appearance of three new stretching frequencies within the range $\left(1900-2200 \mathrm{~cm}^{-1}\right)$. 
complex was collected on a filter and washed with ethanol $(3 \times 10 \mathrm{ml})$. It was then dissolved in benzene $(2 \times 25 \mathrm{ml})$ and filtered. Solid potassium chloride (approx. 0.3 g.) was collected on the filter. The filtrate was reduced in volume $(10 \mathrm{ml})$ on vacuum line, and upon careful addition of hexane $(20 \mathrm{ml})$, a pale yellow compound precipitated out and was collected on a filter. The filtrate was finally put on vacuum line and upon removal of the solvent (benzene-hexane), a very bright yellow crystalline solid remained.

Besides potassium hydroxide, other bases were used. They were sodium ethoxide, sodium carbonate, pyridine and tetramethylethylenediamine. The results obtained were similar for all bases tried, except that the rate of reaction was generally much lower with the organic bases. 


\section{Chapter 3}

\section{RESULTS}

\section{Infrared Spectra}

\section{(a) Silyliridium(III) Complexes}

The stretching frequencies of silicon-hydrogen $[\nu(\mathrm{Si}-\mathrm{H})]$ of parent silanes and for carbonyl $\left[{ }^{\nu}(\mathrm{CO})\right]$ and iridium-hydrogen $\left[{ }^{\nu}(\mathrm{Ir}-\mathrm{H})\right]$ of all prepared iridium complexes are listed in Table 3 (pp 43-44).

The ${ }^{\nu}(\mathrm{CO})\left(1920 \mathrm{~cm}^{-1}\right)$ of the starting iridium(I) hydride, $\operatorname{Ir}(\mathrm{CO}) \mathrm{HP}_{3}$, shifted to higher stretching frequencies for the iridium(III) adducts. The range varied from a high of $2010 \mathrm{~cm}^{-1}$ for the trichlorosilyl adduct to a low of $1960 \mathrm{~cm}^{-1}$ for the trimethylsilyl adduct. There was not much difference in shift of the iridium-hydrogen stretching frequencies between starting and final products.

Two bands at $2000 \mathrm{~cm}^{-1}$ and $1963 \mathrm{~cm}^{-1}$ (smear) were observed when triethoxysilane was added to compound $\operatorname{Ir}(C O) D_{3}(1: 1)$. The band at $2000 \mathrm{~cm}^{-1}$ was assigned to CO trans to deuterium in $\operatorname{Ir}(\mathrm{CO}) \mathrm{P}_{2} \mathrm{HDSi}\left(\mathrm{C}_{2} \mathrm{H}_{5} \mathrm{O}\right)_{3}$, while the other band at $1965 \mathrm{~cm}^{-1}$ was assigned to $c 0$ trans to hydrogen in $\operatorname{Ir}(\mathrm{CO}) \mathrm{P}_{2} \mathrm{HDSi}\left(\mathrm{C}_{2} \mathrm{H}_{5} \mathrm{O}\right)_{3}$.

A spectrum showing ${ }^{\nu}(\mathrm{CO})$ and ${ }^{\nu}(\mathrm{Ir}-\mathrm{H})$ stretching frequencies of methyldichlorosilyl-adduct is shown in 
Figure 1 (p 45).

(b) Products of the dehydrochlorination reaction

In the dehydrochlorination of $\operatorname{Ir}(\mathrm{CO}) \mathrm{ClP}_{2} \mathrm{H}_{2}$

in the presence of excess triphenylphosphine, the disappearance of ${ }^{\nu}(\mathrm{Ir}-\mathrm{H})\left(2190 \mathrm{~cm}^{-1}, 2100 \mathrm{~cm}^{-1}\right)$ and ${ }^{\nu}(\mathrm{CO})$ (1980 $\mathrm{cm}^{-1}$ ) stretching frequencies of the starting dihydride and the appearance of two new stretching frequencies at $1920 \mathrm{~cm}^{-1}$ and $2120 \mathrm{~cm}^{-1}$ (measured in $\mathrm{KBr}$ ) were observed. The new bands at $1920 \mathrm{~cm}^{-1}$ and $2120 \mathrm{~cm}^{-1}$ were assigned to ${ }^{v}(\mathrm{CO})$ and ${ }^{v}(\mathrm{Ir}-\mathrm{H})$ respectively of compound $\operatorname{IrH}(\mathrm{CO}) \mathrm{P}_{3}$. However, in the absence of triphenylphosphine, the reaction product yielded three new bands at $2070 \mathrm{~cm}^{-1}$, $1990 \mathrm{~cm}^{-1}$ and $1.920 \mathrm{~cm}^{-1}(\mathrm{KBr})$; the first and last bands being assigned to ${ }^{\nu}(\mathrm{CO})$ and ${ }^{\nu}(\mathrm{Ir}-\mathrm{H})$ respectively of $\operatorname{IrH}(\mathrm{CO}) \mathrm{P}_{3}$; no assignment has been given to the other band.

The product from the reaction of compound $\operatorname{Ir}(\mathrm{CO}) \mathrm{ClD}_{2} \mathrm{P}_{2}$ with base in the presence of excess triphenylphosphine gave three bands at $1945 \mathrm{~cm}^{-1}, 1925 \mathrm{~cm}^{-1}$ and at $2070 \mathrm{~cm}^{-1}(\mathrm{KBr})$; the former being about three times the intensities of the latter bands. The band at $1945 \mathrm{~cm}^{-1}$ was assigned to $\mathrm{CO}$ trans to deuterium in compound $\operatorname{Ir}(\mathrm{CO}) \mathrm{DP}_{3}$ ' while the other two bands were assigned to ${ }^{\nu}$ (CO) and ${ }^{\nu}$ ( $\mathrm{Ir}-\mathrm{H}$ ) respectively of compound $\operatorname{IrH}(\mathrm{CO}) \mathrm{P}_{3}$. 
TABLE 3

(i)

\section{INFRARED SPECTRA}

\begin{tabular}{|c|c|c|c|c|}
\hline COMPOUND & $\begin{array}{c}\text { (Si-H) of } \\
\text { parent silane } \\
\mathrm{cm}^{-1}\end{array}$ & $\begin{array}{l}{ }^{v}(\mathrm{CO}) \\
\mathrm{cm}^{-1}\end{array}$ & $\begin{array}{c}v(\mathrm{Ir}-\mathrm{H}) \\
\mathrm{cm}^{-1}\end{array}$ & \\
\hline $\operatorname{Ir}(\mathrm{CO}) \mathrm{ClP}_{2}$ & & a. 1950 (vs) & & \\
\hline \multirow[t]{3}{*}{$\operatorname{Ir}(\mathrm{CO}) \mathrm{HP}_{3}$} & & a. 1920 (vs) & 2120 (vs) & \\
\hline & & b. $1920(\mathrm{vs})$ & 2070 (vs) & \\
\hline & & c. 1920 (vs) & $2070(s)$ & \\
\hline $\operatorname{Ir}(\mathrm{CO}) \mathrm{H}_{2} \mathrm{P}_{2}\left(\mathrm{SiCl}_{3}\right)$ & b. 2275 (vs) & a. 2010 (vs) & 2117 (vs) & \\
\hline $\operatorname{Ir}(\mathrm{CO}) \mathrm{P}_{2} \mathrm{H}_{2}\left(\mathrm{Si}\left(\mathrm{CH}_{3}\right)_{3}\right)$ & b. $2125(\mathrm{vs})$ & c. 1960 (vs) & obscured & by ${ }^{\nu}(\mathrm{Si}-\mathrm{H})$ \\
\hline \multirow[t]{3}{*}{$\operatorname{Ir}(\mathrm{CO}) \mathrm{H}_{2} \mathrm{P}_{2}\left(\mathrm{Si}\left(\mathrm{C}_{6} \mathrm{H}_{5}\right)_{3}\right)$} & a.2120(vs) & $\begin{array}{l}\text { a. } 1963 \text { (vs) } \\
\text { (iii). }\end{array}$ & 2075 (vs) & $2134(w)$ \\
\hline & & b. - - - & 2075 (vs) & $2134(w)$ \\
\hline & & c. 1963 (vs) & 2075 (vs) & $2134(w)$ \\
\hline \multirow[t]{4}{*}{$\operatorname{Ir}(\mathrm{CO}) \mathrm{H}_{2} \mathrm{P}_{2}\left(\mathrm{Si}\left(\mathrm{C}_{2} \mathrm{H}_{5} \mathrm{O}\right)_{3}\right)$} & b. 2200 (vs) & $\begin{array}{l}\text { a. } 1963 \text { (vs) } \\
\text { (iii) }\end{array}$ & 2075 (vs) & $2120(w)$ \\
\hline & & b. $\cdots-$ & $2090(s)$ & \\
\hline & & c.1966 (vs) & $2090(s)$ & \\
\hline & & d. 1963 (vs) & 2075 (vs) & $2120(w)$ \\
\hline
\end{tabular}




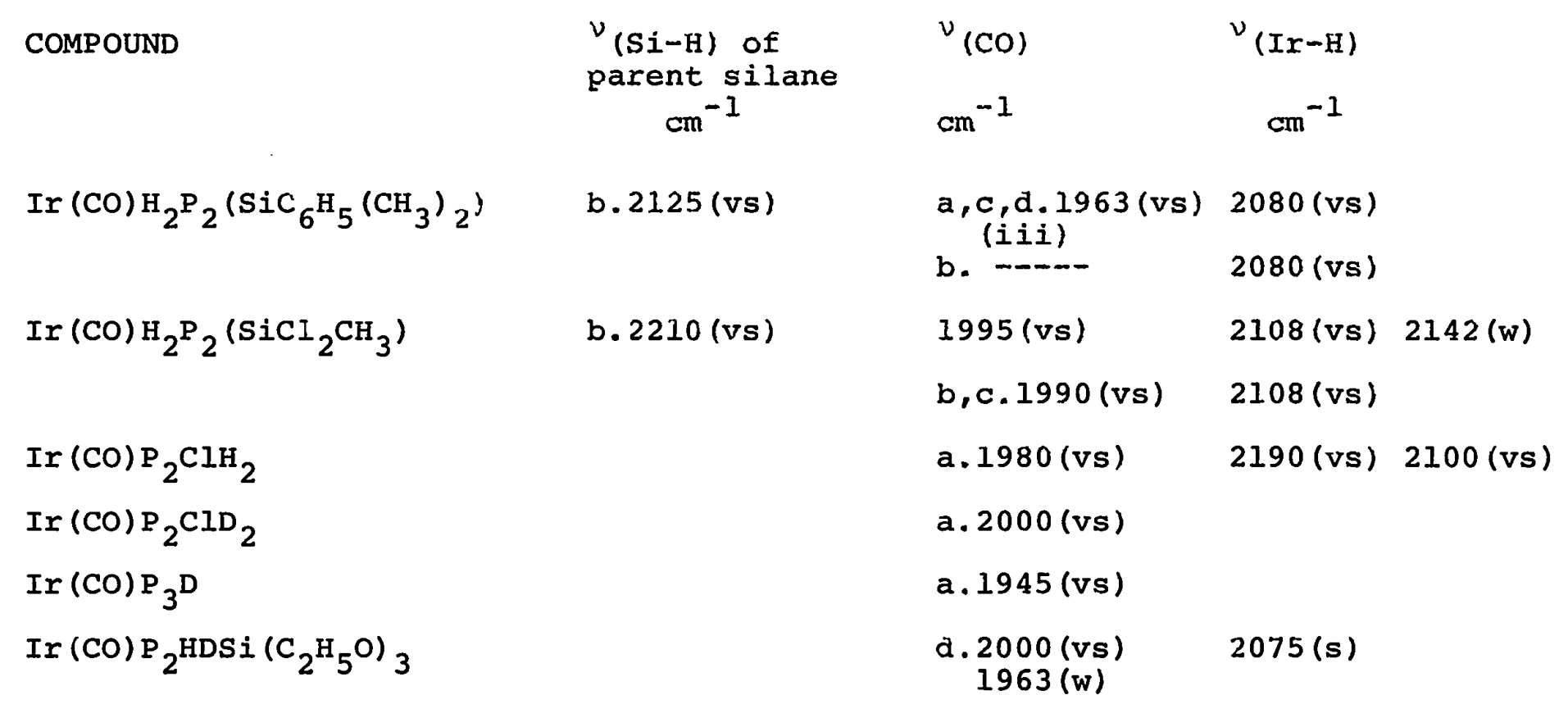

$v$ (CO)

$\mathrm{cm}^{-1}$

a,c,d.1963 (vs) 2080 (vs)

(iii)

b. - - -

2080 (vs)

1995 (vs)

2108 (vs) $2142(w)$

b,c. 1990 (vs)

2108 (vs)

a. 1980 (vs)

2190 (vs) 2100 (vs)

a. 2000 (vs)

a. 1945 (vs)

d. 2000 (vs) $1963(w)$

(i) Intensities of spectral bands are designated by (vs) very strong, (s) strong, (w) weak.

(ii) Spectrum taken in presence of excess silane.

(iii) Hidden in spectral band of benzene.

The notation (a), (b), (c) \& (d) refers to state of sample

(a) $\mathrm{KBr}$ pellet (b) benzene solution (c) dichloromethane solution

(d) smear 
$\nu_{\text {CO AND }} \nu_{\text {Ir-H OF }}$

METHYLDICHLOROSILYLIRIDIUM (III) -ADDUCT

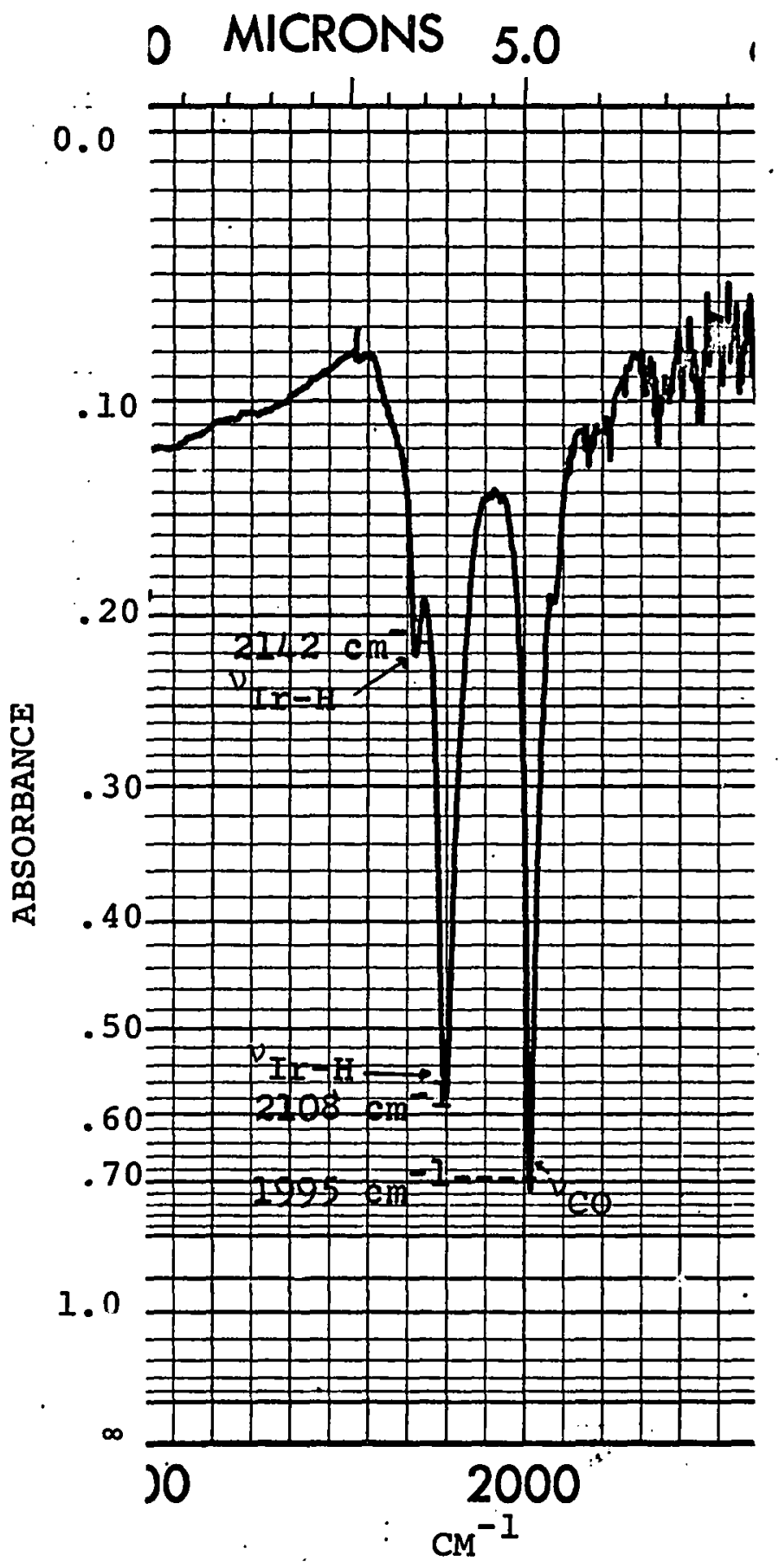

FIGURE 1 
$\underline{1_{\mathrm{H}} \mathrm{nmr} \text { spectra }}$

The coupling constants and the chemical shifts of the triethoxy-, triphenyl- and phenyldimethyl adducts are listed in Table 4.

The structure of the adducts, which are discussed below (cf. p 54) may be taken as:

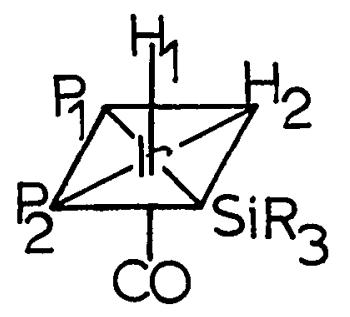

Figure 2 shows the ${ }^{1_{H}} \mathrm{nmr}$ spectrum of the triethoxysilyl adduct with the lines numbered, and a correlation diagram showing assignments of coupling constants and chemical shifts. All products arising from dehydrochlorination of $\operatorname{Ir}(\mathrm{CO}) \mathrm{ClH}_{2} \mathrm{P}_{2}$ in absence or presence of triphenylphosphine gave high field quartets at $20.9 \tau(\mathrm{J}(\mathrm{P}-\mathrm{H})=21 \mathrm{~Hz})\left(\mathrm{CH}_{2} \mathrm{Cl}_{2}\right)$. These spectra were interpreted to be those resulting from compound $\operatorname{Ir}(\mathrm{CO}) \mathrm{P}_{3} \mathrm{H}$. 
TABLE 4

$I_{\text {H }}$ CHEMICAL SHIFTS AND COUPLING CONSTANTS OF IRIDIUM(III) COMPLEXES

\begin{tabular}{|c|c|c|c|c|c|c|c|}
\hline \multirow[t]{2}{*}{$\operatorname{Ir}(\mathrm{CO}) \mathrm{H}_{2} \mathrm{P}_{2} \mathrm{SiR}_{3}$} & \multicolumn{2}{|c|}{$\begin{array}{c}\text { Chemical Shifts } \\
(\tau)\end{array}$} & \multicolumn{5}{|c|}{$\begin{array}{c}\text { Coupling Constants } \\
(\mathrm{Hz})\end{array}$} \\
\hline & $\mathrm{H}_{1}$ & $\mathrm{H}_{2}$ & $J\left(P_{2}-H_{1}\right)$ & $J\left(P_{1}-H_{1}\right)$ & $\mathrm{J}\left(\mathrm{P}_{2}-\mathrm{H}_{2}\right)$ & $J\left(P_{1}-H_{2}\right)$ & $\mathrm{J}\left(\mathrm{H}_{2}-\mathrm{H}_{1}\right)$ \\
\hline $\mathrm{R}_{3}=\left(\mathrm{C}_{\left.2^{\mathrm{H}} 5^{\mathrm{O}}\right)_{3}}\right.$ & 20.2 & 21.5 & 22 & 17 & 110.5 & 18.5 & 4 \\
\hline $\mathrm{R}_{3}=\mathrm{C}_{6} \mathrm{H}_{5}\left(\mathrm{CH}_{3}\right)_{2}$ & 20.04 & 21.0 & 23.5 & 16 & 113.5 & 19.5 & 4.5 \\
\hline $\mathrm{R}_{3}=\left(\mathrm{C}_{6} \mathrm{H}_{5}\right)_{3}$ & 19.5 & 20.7 & 20 & 15.5 & 110.5 & 17 & 4.5 \\
\hline
\end{tabular}


PROTON nMr SPECTRUM IN THE HIGH FIELD REGION AND CORREIATION DIAGRAM OF DIHYDRIDOTRIETHOXYSILYLCARBONYLBIS (TRIPHENYLPHOSPHINE) IRIDIUM (III)

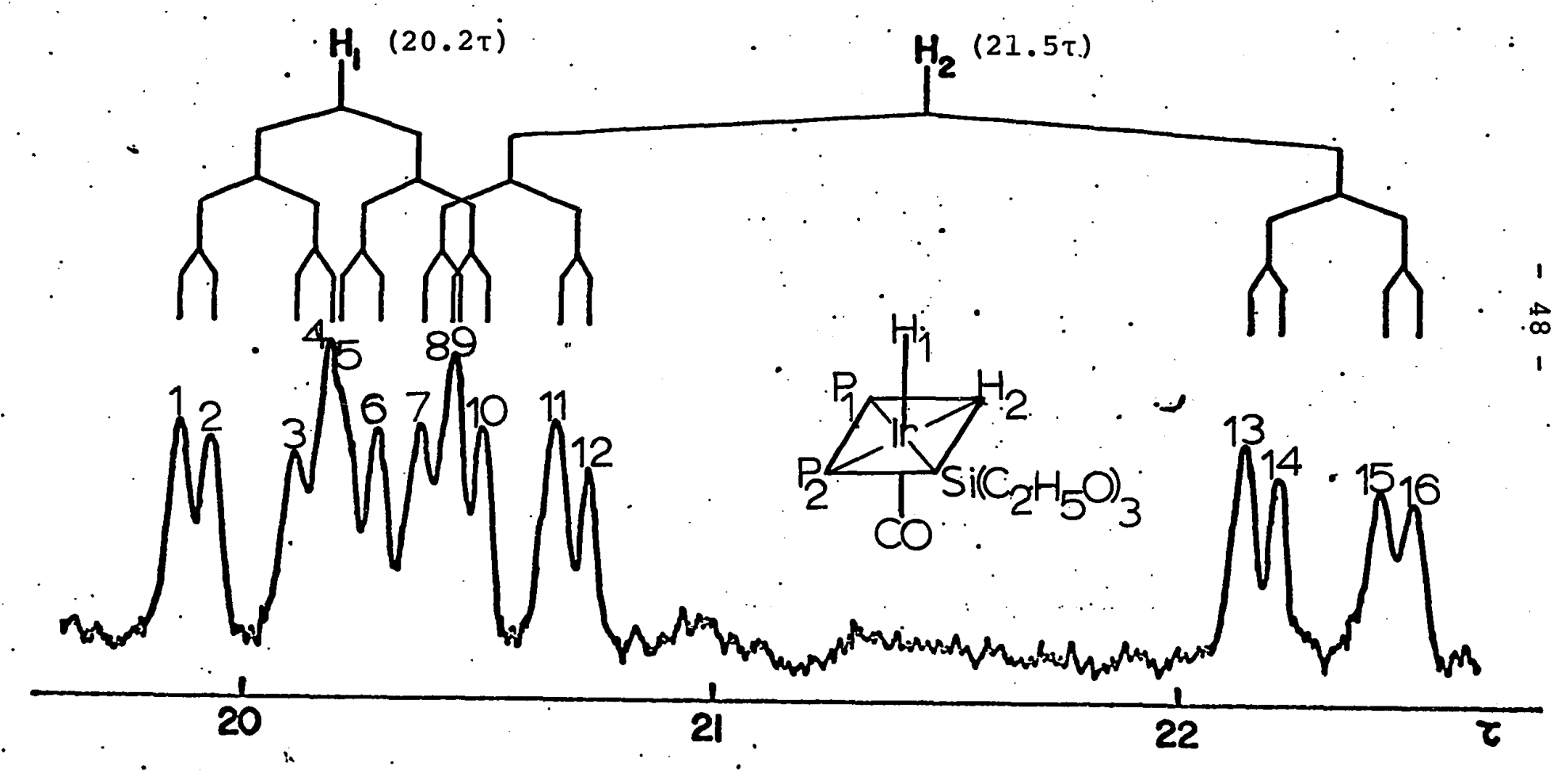

FIGURE 2 


\section{Stoicheiometry}

The combining ratio of silane to iridium(I) complex when verified by elemental analysis was always 1:1. This data is summarized in Table 5 (p 50).

The ratio of triphenylphosphine protons to protons of triethoxysilyl group $\left(\left(\mathrm{C}_{2} \mathrm{H}_{5} \mathrm{O}\right)_{3} \mathrm{Si}\right)$ also indicated 2P:1Si. 
TABLE 5

ELEMENTAL ANALYSES OF SILYLIRIDIUM(III) COMPLEXES

COMPLEXED

SIIANE

Triethoxy

Methyldichloro
Tripheny 1

Trichloro

\author{
ELEMENT PRESENT ( $\%$ \\ C \\ $\mathrm{H}$
}

56.72

5.17

3.08

6.80

Found.

56.68

5.35

2.84

6.63

Calcd.

65.68

4.71

2.79

6.17

Found.

65.87

4.90

3.08

6.09

Calca.

50.4

3.63

3.20

7.04

Found.

51.0

3.83

3.76

6.90

Calca.

53.0

4.1

57.0

4.9

3.3
3.3

7.2

Found. $b$

7.5
4.9

(a) Calculated for $1: 1$ complex

(b) The very high values for $\mathrm{C}, \mathrm{H}$ and $\mathrm{P}$ in this analysis indicate incomplete separation of the product from uncomplexed triphenylphosphine. 


\section{General properties}

Some general properties of the silyliridium(III) complexes are presented in Table 6 . With the exception of the trimethyl adduct, all complexes were stable solids. With the exception of the trichloro and methyldichloro adducts all complexes were sufficiently soluble in dichloromethane to enable measurements of theix ${ }^{I_{H}}$ nuclear magnetic resonance spectra and solution infrared spectra. 
TABLE 6

SOME GENERAL PROPERTIES OF THE SILYLIRIDIUM.(III) COMPLEXES

\begin{tabular}{|c|c|c|c|c|c|c|c|}
\hline \multirow{3}{*}{$\begin{array}{l}\text { COMPLEXED } \\
\text { SILANE }\end{array}$} & \multirow{2}{*}{\multicolumn{2}{|c|}{ QUALITATIVI }} & \multicolumn{4}{|c|}{ (i) } & \multirow[b]{2}{*}{ MELTING } \\
\hline & & & $V E S$ & OLUBI & $\begin{array}{l}\text { ITYY } \\
\qquad i i\end{array}$ & COLOUR & \\
\hline & I & II & III & IV & $\mathrm{V}$ & & POINT $\left(0_{C}\right)$ \\
\hline Triethoxy & v.s. & $\mathbf{s . s}$ & i. & v.s. & v.s. & yellow-white & $152-154$ \\
\hline Trichloro & i. & i. & i. & s.s. & s.s. & white & $\begin{array}{l}\text { dec. at } \\
300\end{array}$ \\
\hline Triphenyl & $\mathbf{s}$. & i. & i. & s. & $\mathbf{s}$ & yellow-white & $\begin{array}{l}\text { dec. at } \\
160\end{array}$ \\
\hline Trimethyl ${ }^{(i i i)}$ & s. & - & - & s. & - & ---- & ---- \\
\hline PhenyldimethyI & v.s. & s.s & i. & v.s. & v.s. & yellow-white & $\begin{array}{l}\text { dec. at } \\
165\end{array}$ \\
\hline Methyldichloro & i. & i. & i. & s.s. & s.s. & white & $\begin{array}{l}\text { dec. at } \\
300\end{array}$ \\
\hline
\end{tabular}

(i) Solubilities were determined by visual inspection. They are denoted as: $i$. insoluble, s.s. slightly soluble, s. soluble, v.s. very soluble.

(ii) I= Benzene, II= Hexane, III= Ethanol, IV= Dichloromethane, $\mathrm{V}=$ Chloroform.

(iii) Preparation of adduct was made in benzene and dichloromethane solutions but solid was not isolated. 
Chapter 4

DISCUSSION

A. SILYLIRIDIUM (III) COMPLEXES

(i). General properties

All of the silicon hydrides investigated were found to undergo reaction with hydridocarbonyltris(triphenylphosphine)iridium(I) (A) according to reaction [19]:<smiles></smiles>

(A)
$+\mathrm{R}_{3} \mathrm{SiH}$

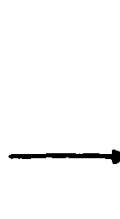

(B)

where $R_{3}=$ triethoxy, triphenyl, trimethyl, trichloro, methyldichloro and phenyldimethyl.

The oxidative addition of silicon hydrides to chlorocarbonylbis (triphenylphosphine)iridium(I) was previously studied (14) but the reaction was limited to silicon hydrides bearing electronegative substituents. However, hydridocarbonyltris (triphenylphosphine) iridium (I) reacted readily with all the silicon hydrides tried, even triaryl and trialkyl-silanes yielded relatively stable products. 
The stereochemistry of the adducts was established by proton nmr and infrared spectroscopies. Chemical analyses were obtained for the crystalline products resulting from additions of triphenylsilane, triethoxysilane and trichlorosilane. These analyses confirmed $1: 1$ adducts. Although difficulties were experienced in obtaining adducts with other silicon hydrides that were sufficiently pure for chemical analysis, the similarity of the infrared or $\mathrm{nmr}$ spectra of all the adducts leaves little doubt that they were isostructural.

\section{(ii). Proton nmr spectra}

Good proton nmr spectra were obtained for three of the adducts. The high field hydride spectra of all three complexes were virtually identical and consisted of sixteen lines. Figure 2 (p 48 ) shows the proton $\mathrm{nmr}$ spectrum of the triethoxysilyl adduct, with a correlation diagram indicating coupling constants. Eight of the lines (nos. $1,2,3,4,5,6,8$ and 10 ) were assigned to the proton $\left(\mathrm{H}_{1}\right)$ in complex (B), coupling to two cis phosphines and a second hydride $\left(\mathrm{H}_{2}\right)$. The other eight lines arising from coupling of the proton $\left(\mathrm{H}_{2}\right)$ with a cis and trans phosphine and with the proton $\left(\mathrm{H}_{1}\right)$.

The chemical shifts and coupling constants are given in Table 4 (p 47$)$. As in other transition-metal 
hydrido-complexes (cf Table 1 p 17), the chemical shifts are large ( $\tau$ values ranging from 19.5-21.5 $\tau$ ). It is known that the coupling constants for the interaction between a hydrogen nucleus and phosphorus nucleus in cis position are in the range $10-40 \mathrm{~Hz}$, but for a phosphorus nucleus in trans position the range is from 80-160 Hz. Therefore the coupling constant of $110.5 \mathrm{~Hz}$ observed in the case of the triethoxysilyl adduct, was assigned to interaction between phosphine ligand $\left(\mathrm{P}_{2}\right)$ trans to the proton $\left(\mathrm{H}_{2}\right)$;

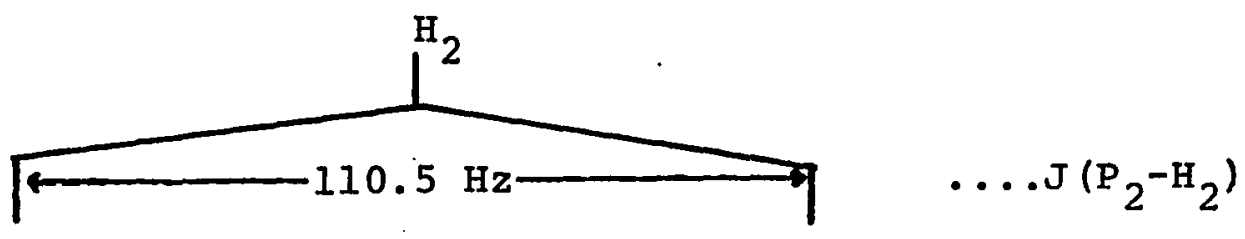

This proton was further split and a coupling of $19 \mathrm{~Hz}$ was observed. This interaction is typical for cis phosphorus-hydrogen interactions, consequently it was assigned to interaction between phosphine ligand $\left(\mathrm{P}_{1}\right)$ with proton $\left(\mathrm{H}_{2}\right)$;

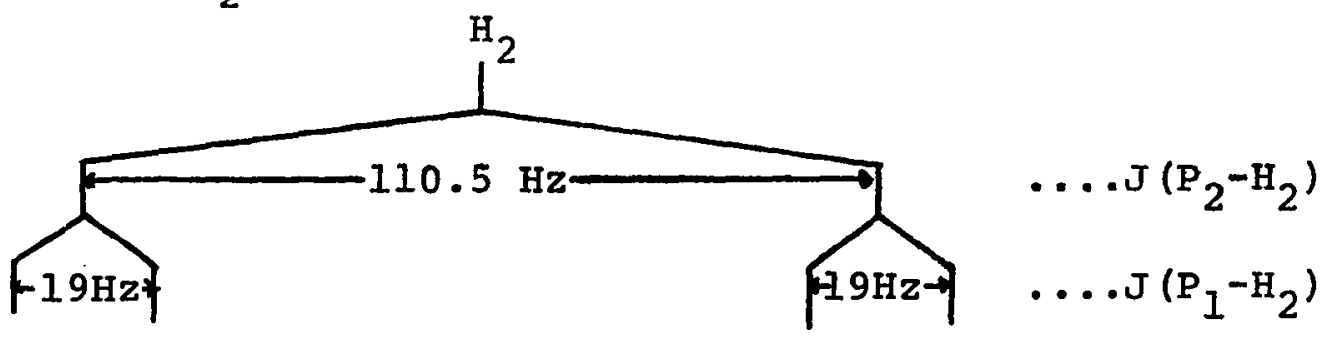


Finally proton-proton interaction of $4 \mathrm{~Hz}$ was observed;

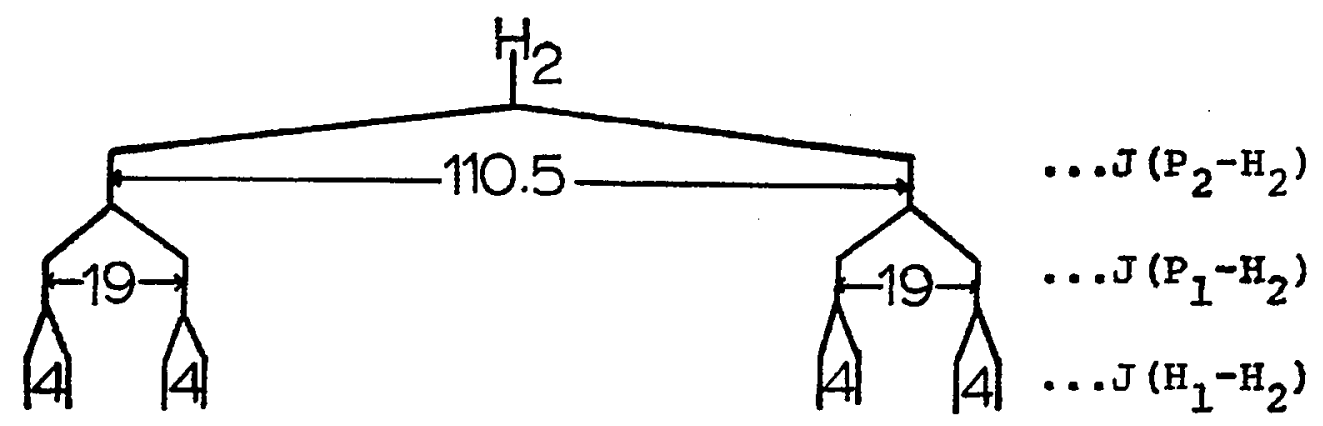

Similarly, the coupling constants may be assigned to phosphine ligands, $\mathrm{P}_{1}$ and $\mathrm{P}_{2}$, and proton $\left(\mathrm{H}_{2}\right)$ interactions with proton $\left(\mathrm{H}_{1}\right)$. Phosphine ligand $\left(\mathrm{P}_{2}\right)$, which is cis to proton $\left(\mathrm{H}_{1}\right)$, gave a coupling constant of $22 \mathrm{~Hz}$;

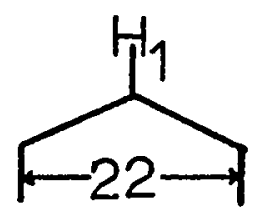$$
\ldots . . J\left(\mathrm{P}_{2}-\mathrm{H}_{1}\right)
$$

while phosphine ligand $\left(\mathrm{P}_{1}\right)$, also cis, gave a coupling constant of $17 \mathrm{~Hz}$;

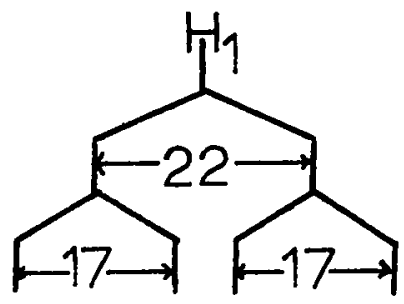

$$
\begin{aligned}
& \ldots . \mathrm{J}\left(\mathrm{P}_{2}-\mathrm{H}_{1}\right) \\
& \ldots . \mathrm{J}\left(\mathrm{P}_{1}-\mathrm{H}_{1}\right)
\end{aligned}
$$


Finally a coupling constant of $4 \mathrm{~Hz}$ was observed and this was assigned to proton $\left(\mathrm{H}_{2}\right)$-proton $\left(\mathrm{H}_{1}\right)$ interaction;

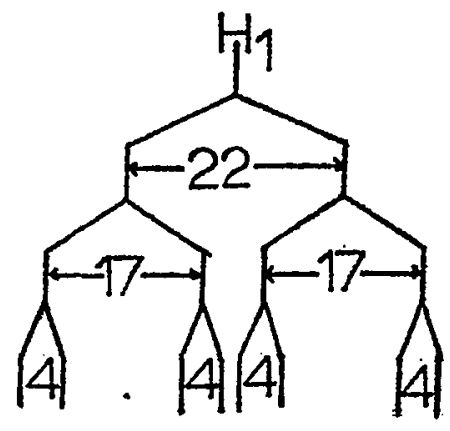

The nmr spectra of these complexes allowed an unequivocal assignment of the phosphine and hydridic ligands as shown in complex (B), but the relative positions of the carbonyl and silyl ligands remained uncertain. It may be pointed out that the insensitivity of the nmr chemical shift and the coupling constants to the variation of the substituents on the silicon indicated that the silicon was trans to neither hydride ligand. This observation, however, is not conclusive evidence for an unequivocal assignment of the silyl ligands. A study of the infrared spectra of adducts of the deuteride analogue of $(A)\left(1-d, \operatorname{Ir}(C O) D_{3}\right)$ did, however place the position of the carbonyl group in (B). 


\section{(iii). Infrared spectra}

The hydrido-carbonyl iridium(III) complexes showed very strong infrared absorptions at ca. $2100 \mathrm{~cm}^{-1}$ due to the iridium-hydrogen stretching mode, and at ca. $1970 \mathrm{~cm}^{-1}$ due to the carbonyl stretching modes. Complete infrared data are given in Table 3 (p 43) The carbonyl [ $\left.{ }^{\nu}(\mathrm{CO})\right]$ absorption in such complexes is very sensitive to the charge of the central metal ion, moving to higher frequencies as the positive charge on the metal ion increases. From Table 3, it is evident that such a pattern is observed. The ${ }^{v}(\mathrm{CO})$ varied from $2010 \mathrm{~cm}^{-1}$ for the highly electronegative trichlorosilyl group to $1960 \mathrm{~cm}^{-1}$ for the trimethylsilyl group, some 90-40 $\mathrm{cm}^{-1}$ higher than the ${ }^{v}(\mathrm{CO})$ of the starting iridium.(I) complex.

Addition of up to one equivalent of silicon hydride to $\operatorname{Ir}(C O) D_{3}(1-d)$ led to the disappearance of the iridium(I) carbonyl band $\left(1945 \mathrm{~cm}^{-1}\right)$ and the appearance of a new carbonyl band $\left(=2000 \mathrm{~cm}^{-1}\right)$ about $40 \mathrm{~cm}^{-1}$ higher in frequency than that obtained for the hydride complex. This resonance shift of ${ }^{v}(\mathrm{CO})$ indicated that the deuterium was ending up trans to the carbonyl group in the adduct and the stereochemistry of the reaction is as shown in reaction [20]:

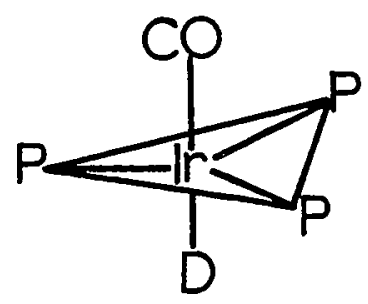

$(1-4)$
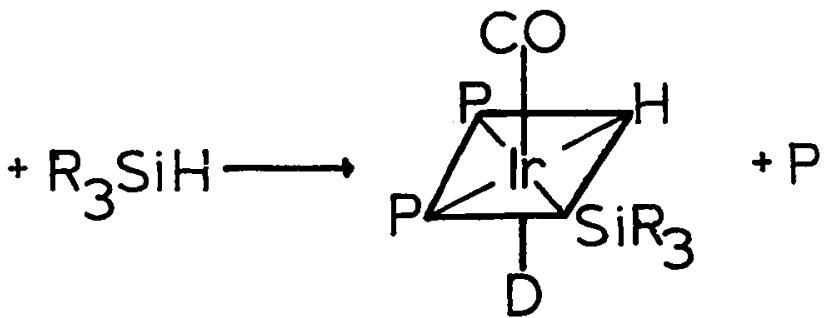

$(2-4)$ 
Both infrared and $\mathrm{nmr}$ spectra of adducts freshly prepared were invariant with time and identical with those of the purified complexes. It thus seems probable that the stereochemistry observed is that of the primary reaction product (p 53). That is, the characteristics of this stereochemistry are cis addition of the addend and retention of the residual ligand geometry, with loss of phosphine ligand.

From Table 3 (p 43) it appears that there is a rough correlation between the ${ }^{v}(\mathrm{Si}-\mathrm{H})$ of the free silane $\left(2125 \mathrm{~cm}^{-1}\right.$ for $\left(\mathrm{CH}_{3}\right)_{3} \mathrm{SiH}$ and $2275 \mathrm{~cm}^{-1}$ for $\mathrm{Cl}_{3} \mathrm{SiH}$ and the stability of the adduct formed, leading to the apparent anomalous conclusion that the stronger the Si-H bond, the more stable the complex derived from it. This anomaly is readily resolved if one concludes that the influences leading to a strengthening of the Si-H bond are even more effective in bonding the silicon to iridium. In any event, one would expect the presence of electronegative substituents to enchance the stability of a silyl-like ligand by raising the effective positive charge on the metal ion.

The trans effect of the carbonyl and the phosphine ligands are comparable as the closeness of the chemical shifts of the proton trans to these ligands 
showed in nmr data. This fact was confirmed by examination of iridium-hydrogen stretching frequencies in infrared spectra. The dihydride complexes gave one strong peak for ${ }^{\nu}(\mathrm{Ir}-\mathrm{H})$ when spectra were measured in benzene or dichloromethane solution. This may be due to the broadening of the bands when measured in solution, since measurements in $\mathrm{KBr}$ pellets gave one strong band and one weak one for ${ }^{\nu}(\mathrm{Ir}-\mathrm{H})$ stretching frequencies. The bands observed in $\mathrm{KBr}$ pellets measurements may be assigned as assymetrical and symetrical stretching modes, although this cannot be certain with a cis configuration. Figure 1 shows ${ }^{\nu}(\mathrm{CO})$ and ${ }^{\nu}(\mathrm{Ir}-\mathrm{H})$ of the methyldichlorosilyl-adduct measured in $\mathrm{KBr}$ pellet.

No iridium-deuterium stretching frequencies were observed and reported for the iridium deuteride complexes since these bands were obscured by the spectral bands due to the triphenylphosphine ligands. 


\section{B. THERMAL STABILITY}

One of the original objectives in this

present investigation was to prepare silyliridium(I) complexes by reductive elimination of the hydrogen from the silicon hydride adducts described above:

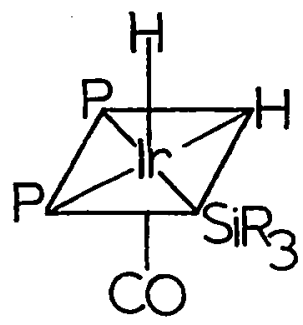

(B)

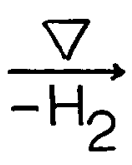

(C)

However, none of the complexes lost hydrogen on heating to the point of destructive decomposition, either in the presence or absence of excess triphenylphosphine. It would therefore appear that the complex (C), if it could be prepared would prove to give an exceptionally stable dihydride by the reverse of reaction [21]. Such behaviour would be in line with the generally observed trend (50) that very "soft" or polarizable ligands promote stability in the six co-ordinate $d^{6}$ species relative to the four and five co-ordinate $d^{8}$ species. 


\section{EXCHANGE WITH DEUTERIUM}

As mentioned earlier, adäition of triethoxysilane to complex $1-\mathrm{d}, \operatorname{Ir}(\mathrm{CO}) \mathrm{DP}_{3}$, resulted in an adduct which exhibited two carbonyl bands at $1965 \mathrm{~cm}^{-1}$ and at $2000 \mathrm{~cm}^{-1}$, and gave an $\mathrm{nmr}$ spectrum identical to that shown in Figure 2 (p 48) except that the $\mathrm{H}-\mathrm{H}$ coupling was no longer evident. These results indicated that the deuterium was equally distributed between the two hydride positions of complex (B). The carbonyl band at $2000 \mathrm{~cm}^{-1}$ was assigned to the $\mathrm{CO}$ trans to deuterium.

In the presence of excess triethoxysilane, hydridodeuteridotriethoxysilylcarbonylbis (triphenylphosphine)iridium(III) undergoes rapid exchange. This exchange could be rationalized by assuming that the oxidative addition reaction [19] is a rapid equilibrium, by repetitive oxidative addition and reductive elimination, (as in fact can be clearly demonstrated with trimethylsilane):
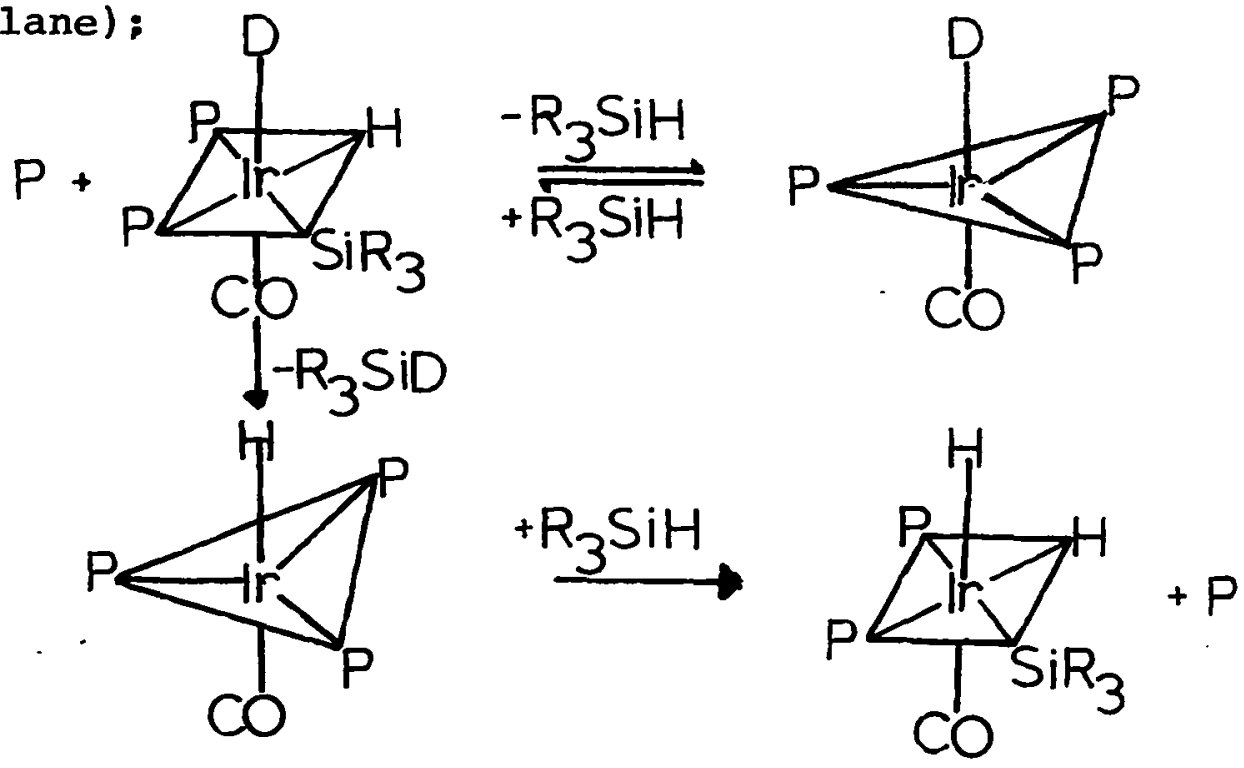
Shaking a benzene solution of complex (B) $\left(\mathrm{R}_{3}=\left(\mathrm{C}_{2} \mathrm{H}_{5} \mathrm{O}\right)_{3}\right)$ under one atmosphere of deuterium at room temperature for 18 hours resulted in the disappearance of the weak ${ }^{\nu}(\mathrm{Ir}-\mathrm{H})$ band but no shift in ${ }^{\nu}(\mathrm{CO})$. It was thought that a complete exchange of the hydride trans to the phosphine ligand had occurred according to reaction [23];
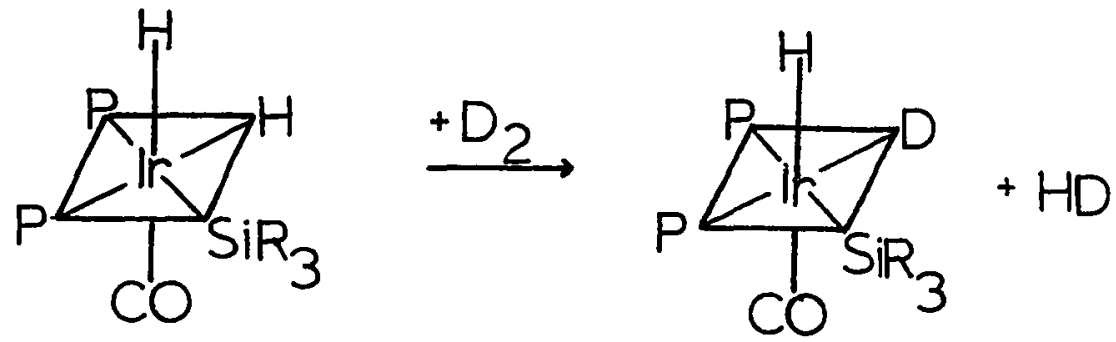

However nmr measurements disproved such a reaction, since no noticeable change was observed in $\mathrm{nmr}$ spectrum when compared to the spectrum of triethoxysilyl adduct. Infrared spectrum showed no ${ }^{\nu}$ (Ir-D) band for same reason as outlined on $\mathrm{p} 60$. 


\section{Chapter 5}

DEHYDROCHLORINATION OF CHLORODIHYDRIDOCARBONYLBIS (TRIPHENYLPHOSPHINE) Ir (III) IN THE PRESENCE OF STRONG BASES

Activation of molecular hydrogen by metal ions may be classified into three types of reaction:

$$
\begin{aligned}
\mathrm{ML}+\mathrm{H}_{2} & \longrightarrow \mathrm{MH}+\mathrm{LH}^{+} \\
2 \mathrm{M}+\mathrm{H}_{2} & \longrightarrow 2 \mathrm{MH} \\
\mathrm{M}+\mathrm{H}_{2} & \longrightarrow \mathrm{H}-\mathrm{M}-\mathrm{H}
\end{aligned}
$$

In reaction [24] the hydrogen molecule is split heterolytically, the hydride fragment entering the co-ordination sphere of the metal ion. This reaction is essentially a substitution process in which the formal oxidation state of the metal remains unchanged.

Reactions [25] and [26] involve homolytic scission of the hydrogen molecule and the metal ions undergo changes in oxidation state of one and two respectively. The first known example of reaction [26] was the addition of hydrogen to chlorocarbonylbis (triphenylphosphine)iridium (I) (D) (18). The dihydride product (E) of this reaction readily loses hydrogen and reverts back to the original iridium(I) complex:

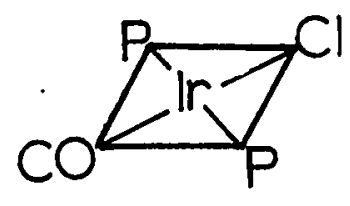

(D)
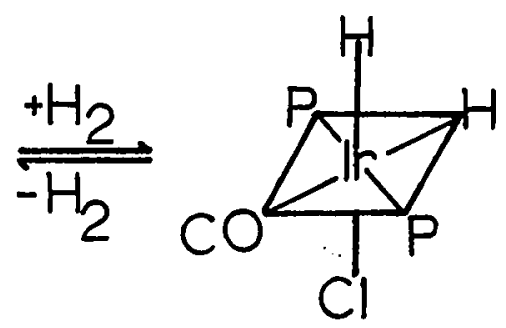

(匹) 
In principle the dihydride (E) could also lose a molecule of $\mathrm{HCl}$ by either cis or trans elimination, to yield the hydridoiridium (I) species (F):

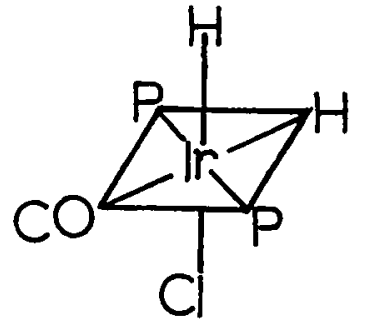

(E)

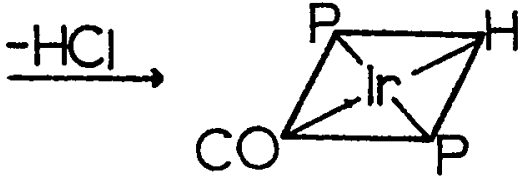

(F)

Such a reaction has not previously been reported and presumably does not occur because the $\mathrm{HCl}$ bond strength is considerably less than the sum of the $\operatorname{Ir}($ III) $-\mathrm{H}$ and Ir (III)-Cl bonds strengths. However, in the presence of bases stronger than $\mathrm{Cl}^{-}$, it was anticipated that proton elimination from the complex (E) would occur.

The above prediction has been shown to be, at least in principle, correct in as much as the elimination of the HCl from compley (E) was found to occur with sodium ethoxide, pyridine, tetramethylethylenediamine and potassium hydroxide as proton acceptors. However, the product isolated from the reaction was not complex (F), but a mixture of two compounds, (G) and (H) in roughly equal quantities. One of these compounds (G), proved to be the known complex hydridocarbonyltris (triphenylphosphine)iridium(I) (A) and was characterized by proton $\mathrm{nmr}$ ( high field quartet $\tau=20.9, \mathrm{~J}=21 \mathrm{~Hz}$ in $\mathrm{CH}_{2} \mathrm{Cl}_{2}$ ) and by infrared 
spectroscopy $I^{\nu}(\mathrm{Ir}-\mathrm{H})=2070 \mathrm{~cm}^{-1},{ }^{\nu}(\mathrm{CO})=1920 \mathrm{~cm}^{-1}$ in benzene) (M.P. $163^{\circ} \mathrm{C}$ ). The other compound has not as yet been characterized.

Treatment of complex (E) with one equivalent of potassium hydroxide in refluxing ethanol, in the presence of three equivalents of triphenylphosphine, gave compound (A) in high yield. These observations indicate the elimination of $\mathrm{HCl}$ from (E) occurs under basic conditions, but suggest that complex (F) is unstable with respect to disproportionation, driven by the tendency of complex (F) to expand its co-ordination sphere. That the hydride of complex (A) is that originally present in compound (E) was demonstrated by the fact that the deuteride analogue of (E) reacting under the conditions described above, gave the deuteride analogue of (A) ( 758) rather than the hydride, in spite of the fact that the reaction was carried out with potassium hydroxide in vast excess of normal ethanol.

The preparation of complex (F) has been previously described by Malatesta (35), using several independent synthetic routes. Rather surprisingly, the infrared data cited by Malatesta for complex (F) coincided exactly with the data obtained for.the mixture of complexes (G) and (H). In addition, the compound prepared by Malatesta exhibited two infrared absorptions due to the carbonyl group, when 
the spectrum was measured in $\mathrm{KBr}$. All other known analogues of structure $\operatorname{Ir}(C O) X_{2}$ exhibit one carbonyl band.

In view of the above anomalies two of the syntheses of complex (F) described by Malatesta were performed. The first one involved carbonylation of iridium tetraiodide followed by reaction with triphenylphosphine in ethanolic potassium hydroxide. Care was taken in the addition of triphenylphosphine, since a similar reaction with excess triphenylphosphine gave complex (A), Ir (CO) $\mathrm{HP}_{3}$ : However, the product from this reaction gave the same results and data as that obtained when the dihydride (E) was reacted with base in the absence of triphenylphosphine.

The second experiment performed was an attempt at reductive elimination of trihydridocarbonylbis (triphenylphosphine)iridium(III), (J). It was pointed out by Malatesta (35) that bubbling nitrogen for four hours through a benzene solution of (J) yielded complex (F). When this experiment was performed, no change was observed as shown by infrared measurements although nitrogen was bubbled through a solution of (J) for 48 hours.

The reactions of base with the dihydride (E) in the absence of triphenylphosphine was performed under atmospheres of (a) nitrogen, (b) hydrogen and (c) carbon monoxide. The results and products, as outlined above, 
were the same when the reaction was carried out under nitrogen and hydrogen. However, when performed under carbon monoxide, a new product was obtained. Infrared measurements showed bands at $1955 \mathrm{~cm}^{-1}$ and $1930 \mathrm{~cm}^{-1}$ due to ${ }^{\nu}(\mathrm{CO})$ and one at $2070 \mathrm{~cm}^{-1}$; nmr measurements on a freshly prepared sample in dichlormethane gave a high field quintet $(\tau=20.9, J=21 \mathrm{~Hz})$. This quintet changed to a quartet $(\tau=20.9 ; \mathrm{J}=21 \mathrm{~Hz})$ when $\mathrm{nmr}$ of sample was taken several hours later. Attempts to repeat this experiment failed and similar results were obtained as were in the case when nitrogen and hydrogen atmospheres were used.

The quintet may have resulted from a dimer of (F), the product joined by bridging hydrogens:

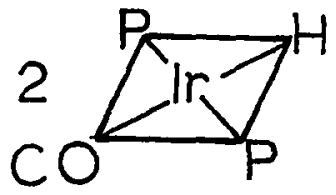

$(F)$
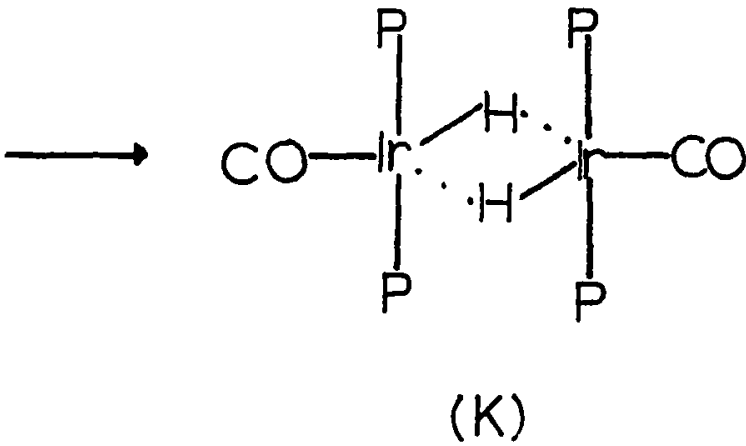

Both species (F) and (K) are apparently unstable with respect to disproportionation and disproportionate to complex (A). 


\section{Chapter 6}

\section{A. CONCLUSIONS}

The co-ordinatively saturated $d^{8}$ complex, hydridocarbonyltris (triphenylphosphine) iridium (I) , reacted with several silicon hydrides giving octahedral $d^{6}$ complexes with loss of neutral phosphine ligand in the process. Cis addition was observed for all complexes prepared. It was interesting to note that the stereochemical course of these reactions was the same as that previously observed by Collman for the oxidative addition to penta-co-ordinate $\mathrm{Ru}(0)(32)$ and $\mathrm{Os}(0)$ (23) complexes.

It was surprising to discover that the structure of the adducts formed was one in which the phosphine ligands were cis to each other, since all other analogous bisphosphine complexes for which structures had been reported contained the phosphines in the trans position.

It is not possible to propose a definite mechanism for these reactions since the rate of addition is extremely fast (54). Although a Collman two step mechanism cannot be ignored (23), it is more probable that the five co-ordinate $d^{8}$ complex $\operatorname{Ir}(\mathrm{CO}) \mathrm{HP}_{3}$ reacted through dissociation of a phosphine ligand prior to 
oxidative addition. Wilkinson has recently suggested such a mechanism for some reactions of the Rh(I) analogue. The $\mathrm{Rh}$ intermediate, $\mathrm{Rh}(\mathrm{CO}) \mathrm{HP}_{2}$, has not been isolated but the iridium intermediate is supposedly stable and has been isolated. It is the belief, however, of the author that this $d^{8}$ unsaturated complex of iridium (I), Ir $(\mathrm{CO}) \mathrm{HP}_{2}$, is most unstable.

The role of group VIII metal complexes as hydrosilation catalysts has been discussed in terms of analogies between the reactions of such complexes with silicon hydride and with hydrogen (cf. p 6 ). Reactions involving $\operatorname{Co}(0), \operatorname{Ir}(I)$ (unsat.), $\mathrm{Pt}(\mathrm{II})$ and $\mathrm{Rh}(\mathrm{I})$ have been discussed. The reactions with the saturated $d^{8}$ iridium(I) complex, $\operatorname{Ir}(\mathrm{CO}) \mathrm{HP}_{3}$, and silicon hydrides parallel those between the $\operatorname{Ir}(I)$ (unsat.) complex, $\operatorname{IrCOClP}_{2}$, with silicon hydrides. The stereochemistry of the complexes resulting from the latter reactions is unknown, but six co-ordinated $d^{6}$ iridium(III) complexes were suggested from infrared data. However, six co-ordinate $d^{6}$ iridium(III) complexes resulted from the former reactions, and the stereochemical course of the reactions is known to be cis addition of the silanes.

The complexes of $\operatorname{Ir}(I)$ (unsat.), $\mathrm{Rh}(\mathrm{I}), \mathrm{Pt}$ (II) and $C o(0)$ which have been reacted with silicon hydrides, 
also reacted with molecular hydrogen. In the case of hydridocarbonyltris (triphenylphosphine) iridium(I), there is no definite proof of this complex adding molecular hydrogen, although Vaska (4) has claimed that hydrogen will add to hydridocarbonyltris (triphenylphosphine)iridium(I) giving a seven co-ordinated trihydride iridium(III) complex, $\operatorname{Ir}(\mathrm{CO}) \mathrm{H}_{3} \mathrm{P}_{3}$. The existence of such a complex is doubtful since electrons would have to be placed in the antibonding orbitals to accommodate seven ligands in a complex of $d^{6}$ configuration. Such a product is contrary to what was observed and obtained when hydridocarbonyltris(triphenylphosphine)iridium(I) was reacted with silicon hydrides.

The six co-ordinated trihydride iridium(III) complex, $\operatorname{Ir}(\mathrm{CO}) \mathrm{H}_{3} \mathrm{P}_{2}$, has been prepared and proved to be stable (35). $\operatorname{IrH}_{3} \mathrm{P}_{3}$ (36) and $\operatorname{IrH}_{3} \mathrm{P}_{2}$ (35) have been prepared and upon addition of $\mathrm{CO}$ to $\operatorname{IrH}_{3} \mathrm{P}_{2}$, the unsaturated iridium (I)monohydride, $\operatorname{Ir}(\mathrm{CO}) \mathrm{HP}_{2}$, was suggested. Malatesta (35) claimed that $\operatorname{Ir}(\mathrm{CO}) \mathrm{H}_{3} \mathrm{P}_{2}$ will lose one mole of hydrogen by bubbling nitrogen through a solution of the complex. However, no reaction was reported in which $\mathrm{CO}$ was reacted with $\operatorname{IrH}_{3} \mathrm{P}_{3}$. Such a reaction should give Ir (CO) $\mathrm{HP}_{3}$ with loss of hydrogen and not a seven co-ordinated trihydride. 
Vaska has claimed that $\operatorname{Ir}(\mathrm{CO}) \mathrm{HP}_{3}$ is an efficient homogeneous catalyst for the hydrogenation of olefins. However it is inactive as a catalyst in hydrosilation reactions ( 8 ). Although the complex is capable of activating the silane ( $\mathrm{Si}-\mathrm{H}$ bond cleavage) as shown by its reaction with various silanes, its ineffectiveness as a homogeneous catalyst in hydrosilation reactions is probably due to the inability of the olefin to co-ordinate it.

Cobalt hydrocarbonyl was demonstrated to react with silicon hydride (16) as in equation [30]:

$$
\mathrm{HCO}(\mathrm{CO})_{4}+\mathrm{R}_{3} \mathrm{SiH} \longrightarrow \mathrm{R}_{3} \mathrm{SiCo}(\mathrm{CO})_{4}+\mathrm{H}_{2}
$$

The loss of hydrogen is observed rather than the elimination of a carbonyl ligand, and a five co-ordinated Co(I) complex is obtained rather than the expected six co-ordinated complex. This reaction is in accord with the hypothesis that $\mathrm{Co}(\mathrm{I})$ is much less reactive as far as oxidative addition reactions of $d^{8}$ complexes are concerned than $\operatorname{Ir}(I)$.

A preparation for hydridocarbonyltris(triphenylphosphine)iridium(I) with high yield was achieved by the novel method of the dehydrochlorination of dihydridocarbonylchlorobis (triphenylphosphine)iridium(III) with various bases in the presence of excess of triphenylphosphine. 
However, several interesting reactions came to life in the search for the above preparation. It was thought that hydridocarbonylbis (triphenylphosphine) iridium(I) would result from the dehydrochlorination of $\operatorname{Ir}(\mathrm{CO}) \mathrm{ClP}{ }_{2} \mathrm{H}_{2}$ with base in the absence of triphenylphosphine. Such a complex though, proved to be most unstable contrary to the result of Malatesta et al.

There are several factors influencing the tendency of co-ordinatively unsaturated $d^{8}$ complexes to achieve co-ordinative saturation by taking up a fifth ligand. Upon ascending a triad or passing from right to left within group VII, the trend is for $d^{8}$ complex to become co-ordinatively saturated. This trend would permit the existence of hydridocarbonylbis(triphenylphosphine) iridium(I), $\operatorname{Ir}(\mathrm{CO}) \mathrm{HP}_{2}$, since iridium(I) complexes should have a tendency to be four co-ordinate. Planar $d^{8}$ complexes are capable of forming three $d-\pi$ back bonds but trigonal-bipyramidal $d^{8}$ complexes can form four such $\pi$ bonds. In the presence of effective $\pi$-acceptor ligands, an increase in electron density at the central metal stablizes the five co-ordinate form. The hydrogen ligand should have a greater tendency than $\mathrm{I}$ or $\mathrm{Cl}$ in the promotion of a complex such as $\operatorname{Ir}(\mathrm{CO}) \mathrm{XP}_{2}(\mathrm{X}=\mathrm{H}, \mathrm{Cl}, \mathrm{I})$ to a more stable five co-ordinate complex. The stability 
of the five co-ordinate formed when a ligand $\mathrm{Y}$ is added;
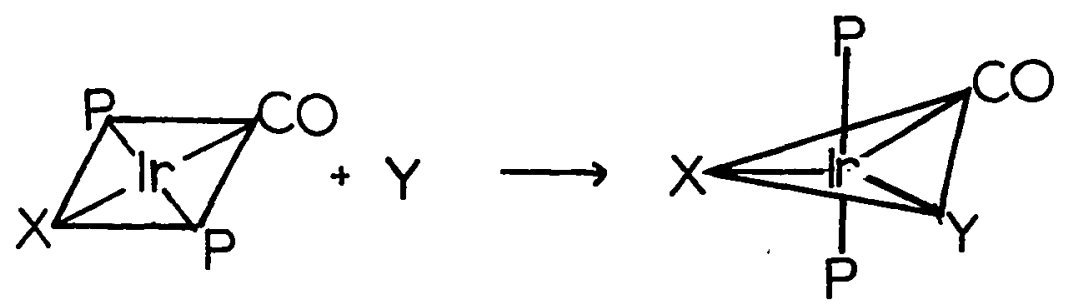

follows the order $\mathrm{X}=\mathrm{H}>\mathrm{I}>\mathrm{Cl}$.

It is a known fact that the co addition to $\operatorname{Ir}(\mathrm{CO}) \mathrm{XP}_{2}$ when $\mathrm{X}=\mathrm{I}$ gives a more stable five coordinate product than when $\mathrm{X}=\mathrm{Cl}$ (55). Oxygen adds to $\operatorname{Ir}(\mathrm{CO}) \mathrm{XP}_{2}$ irreversibly when $\mathrm{X}=\mathrm{I}$ and reversibly when $\mathrm{x}=\mathrm{Cl}$. The equilibrium constant for the hydrogen adduct of $\operatorname{Ir}(\mathrm{CO}) \mathrm{XP}_{2}$ is greater for $\mathrm{X}=\mathrm{I}$ than for $\mathrm{X}=\mathrm{Cl}$. It is therefore logical that the hydrogen adduct of $\operatorname{Ir}(\mathrm{CO}) \mathrm{XP}_{2}$, when $\mathrm{X}=\mathrm{H}$, ( to give $\operatorname{Ir}(\mathrm{CO}) \mathrm{P}_{2} \mathrm{H}_{3}$ ) should prove to have a greater stability than when $\mathrm{x}=\mathrm{I}$ or $\mathrm{Cl}$. Therefore it was not surprising that no change was observed when nitrogen was bubbled through a solution of $\operatorname{Ir}(\mathrm{CO}) \mathrm{P}_{2} \mathrm{H}_{3}$. The oxygen adduct of complex $\operatorname{Ir}(\mathrm{CO}) \mathrm{HP}_{2}$, if it existed, should prove to be extremely stable.

It may be concluded that complex $\operatorname{Ir}(\mathrm{CO}) \mathrm{HP}_{2}$ should have a pronounced inclination to be five co-ordinate, consequently its existence and stability are somewhat doubtful. 


\section{B. SUGGESTIONS FOR FURTHER WORK}

Emphasis must be given to the study of oxidative addition reactions since these reactions are involved in most homogeneous catalysed reactions. The mechanisms and rates of such reactions are very important if catalysts with high efficiencies are to be made.

The mechanisms and rates of the silicon hydride reactions reported in this thesis may be studied. However, since these are fast reactions, they must be studied by appropriate techniques. Use of relaxation methods are highly recommended.

A possible method for the preparation of carbonylsilylbisphosphine-iridium(I) complexes may be the dehydrochlorination of the products formed between reaction of $\operatorname{IrCl}(\mathrm{CO}) \mathrm{P}_{2}$ and silicon hydrides. Although the electrophilic character of silicon may lead to base attack on silicon rather than hydride.

The characterization of the unidentified product of the dehydrochlorination of $\operatorname{Ir}(\mathrm{CO}) \mathrm{P}_{2} \mathrm{H}_{2} \mathrm{Cl}$ in the absence of triphenylphosphine may be attempted. Proper separation of mixture, together with good nmr and 
infrared data and chemical analyses of the unidentified substituent should be useful in identifying this unknown.

The catalytic activities of the silyl iridium-dihydrides may be worthwhile venturing into. It was pointed out that $\operatorname{Ir}(\mathrm{CO}) \mathrm{HDSi}\left(\mathrm{C}_{2} \mathrm{H}_{5} \mathrm{O}\right)_{3} \mathrm{P}_{2}$ undergoes rapid exchange with triethoxysilane. In view of the extreme stability of the triethoxy derivative with respect to loss of silicon hydride it seems more probable that these exchange reactions occur by a concerted bimolecular process. A kinetic investigation of such exchange reactions may be undertaken to test the validity of this hypothesis. 


\section{APPENDIX}

There is a great deal of interest in the preparation and properties of iridium(I) complexes of the type trans-Ir $(\mathrm{CO}) \mathrm{XP}_{2}, \mathrm{X}=\mathrm{Cl}, \mathrm{Br}, \mathrm{I} ; \quad \mathrm{P}=$ tertiary phosphine. It was mentioned in this report that there were no reported reactions in which square planar $d^{8}$ iridium complexes of type $\operatorname{Ir}(\mathrm{CO}) \mathrm{XP}_{2}$ were prepared by dehydrohalogenation with base. However since completion of this work, a report on such reactions was reported by Deeming \& Shaw (43). They prepared Ir $(\mathrm{CO}) \mathrm{X}\left(\mathrm{PMe}_{2} \mathrm{Ph}\right)_{2}$, where $\mathrm{X}=$ halogen, by dehydrohalogenation of $\operatorname{Ir}(\mathrm{CO}) \mathrm{XClH}\left(\mathrm{PMe}_{2} \mathrm{Ph}\right)_{2}$ with methanolic solution of sodium methoxide and potassium hydroxide.

The structure of the adducts prepared in this research program was one in which the phosphine ligands were cis to each other. It was mentioned in this report that these adducts were the first examples of bisphosphine complexes with cis phosphines. However since completion of this work Deeming and Shaw (37) have reported that the addition of allyl halides to chlorocarbonylbis (phenyldimethylphosphine) iridium(I) yielded products with mutually cis phosphines. 


\section{BIBLIOGRAPHY}

1. J. Halpern, J.F. Harrod, B.R. James, J. Am. Chem. Soc. 88,5150 (1966).

2. R.D. Cramer, E.L. Jenner, R.V. Lindsay, U.G. Stolberg, J. Am. Chem. Soc. 85, 1691 (1963).

3. J. Halpern, Advan. Catalysis 11, 324 (1954).

4. L. Vaska, Inorg. Nucl. Chem. Letters 1, 89 (1965).

5. J.A. Osborn, F.H. Jardine, J.F. Young, G. Wilkinson, J. Chem. Soc. 1711 (1966).

6. L. Marko, Chem. Ind. (London) 260 (1962).

7. E.N. Frankel, E.P. Jones, C.A. Glass, J. Am. OiI Chemists' Soc. 41,392 (1964).

8. J.F. Harrod, private sommunications.

9. L. Vaska, R.E. Rhodes, J. Am. Chem. Soc. 87, 4970 (1965).

i0. J. Kwaitek, I.L. Mador, J.K. Seyler, "Reactions of Co-ordination Ligands and Homogeneous Catalysis" Advances in Chem. Series, No. 37, Am. Chem. Soc., Washington, D.C. p 201 (1963).

11. J. Halpern, Advan. Catalysis 9, 324 (1954); 11,301 (1958).

12. R.S. Coffey, Chem. Commun. 923 (1967).

13. J.L. Speier, J.W. Ryan, J. Am. Chem. Soc. 86, 895 (1964).

14. A.J. Chalk, J.F. Harrod, J. Am. Chem. Soc. 87, 16 (1965).

15. F. deCharentenay, J.A. Osborn, G. Wilkinson, J. Chem. Soc. 787 (1968).

16. A.J. Chalk, J.F. Harrod, J. Am. Chem. Soc. 89, 1640 (1967).

17. I. Vaska, J.W. Diluzio, J. Am. Chem. Soc. 83, 2784 (1961). 
18. L. Vaska, J.W. Diluzio, J. Am. Chem. Soc. 84 , 679 (1962).

19. For a review see J. Halpern, Ann. Rev. Phys. Chem. 16, 103 (1965).

20. R.C. Taylor, J.F. Young, G. Wilkinson, Inorg. Chem. 5, 20 (1966).

21. J. Chatt, B.L. Shaw, J. Chem. Soc. 2545 (1962).

22. J.P. Collman, W.R. Roper, J. Am. Chem. Soc. 88, $180(1966)$.

23. J.P. Collman, W.R. Roper, J. Am. Chem. Soc. 88, 3504 (1966).

24. R.S. Nyholm, K. Vrieze, Chem. Ind. (London) 318 (1964).

25. R.F. Heck, J. Am. Chem. Soc. 86,2796 (1964).

26. A.C. Cope, R.w. Siekman, J. Am. Chem. Soc. 87, 3272 (1965).

27. J.P. Collman, J.W. Kang, J. Am. Chem. Soc. 89 , - 844 (1967).

28. R. Cramer, G.W. Parshall, J. Am. Chem. Soc. 87, 1392 (1965).

29. L. Vaska, S.S. Bath, J. Am. Chem. Soc. 88 , 1333 (1966).

30. J.P. Collman, C.T. Sears, Jr., Inorg. Chem. I, 27 (1968).

31. J.P. Collman, W.R. Roper, Chem. Commun. 244 (1966).

32. J.P. Collman, W.R. Roper, J. Am. Chem. Soc. 87, 4008 (1965) and references therein.

33. L. Malatesta, M. Angoletta, G. Gaglio, Proc. of $8^{\text {th }}$ International Conference on Co-ordination Chemistry, V. Gutmann, Ed., p 210 (1964).

34. J. Chatt, L.A. Duncanson, B.L. Shaw, Pro. Chem. Soc. 343 (1957).

35. L. Malatesta, M. Angoletta, G. Caglio, J. Chem. Soc. 6974 (1965). 
36. J. Chatt, R.S. Coffey, B.L. Shaw, J. Chem. Soc. 7391 (1965).

37. A.J. Deeming, B.L. Shaw, Chem. Commun. 751, 1968.

38. L. Vaska, S.S. Bath, J. Am. Chem. Soc. 85,3500 (1963).

39. J.M. Jenkins, B.L. Shaw, J. Chem. Soc. 1407 (1966).

40̂. L. Vaska, J. Am. Chem. Soc. 88,4100 (1966).

41. J.M. Jenkins, B.L. Shaw, J. Chem. Soc. 6789 (1965).

42. L. Vaska, Proc. of $8^{\text {th }}$ International Conference on Co-ordination Chemistry, V. Gutmann, Ed., p 99 (1964).

43. A.J. Deeming, B.L. Shaw, J. Chem. Soc. 1887 (1968).

44. R.F. Heck, Advan. Chem. Ser. 49, 181 (1965).

45. M. Orchin, Advan. Catalysis_5, 385 (1953).

46. R.W. Goetz, M. Orchin, J. Org. Chem. 27, 3698 (1962).

47. J.P. Collman, Accounts of Chem. Research 1, 136 (I968).

48. For a review see A.P. Ginsberg "Transition Metal

Chemistry" Vol. 1, Chpt. 3, R.L. Carlin, Ed., Marcel Dekker Inc. N.Y. (1965).

49. For a review see Green and Jones "Advance Inorg. Chem. and Radio Chem." Z7, 115 (1965).

50. J.P. Collman, F.D. Vastine, W.R. Roper, J. Am. Chem. Soc. 90, 2282 (1968).

51. J. Chatt, N.P. Johnson, B.I. Shaw, J. Chem. Soc. 1625 (1964).

52. L. Vaska, J. Am. Chem. Soc. 88, 5325 (1966).

53. J. Halpern, P.B. Chock, J. Am. Chem. Soc. 3511 (1966).

54. C. Smith, private communications.

55. L. Vaska, Science, 152, 769 (1966). 